\title{
HuR-mediated posttranscriptional modification of Cx40 and coronary microvascular dysfunction in type 2 diabetes
}

Rui Si

The University of Arizona

Jody Tori 0. Cabrera

University of California San Diego

Atsumi Tsuji-Hosokawa

The University of Arizona

Lei Gao

University of California San Diego

Rui Guo

The University of Arizona

Makiko Watanabe

The University of Arizona

Yun Sok Lee

University of California San Diego

Jae-su Moon

University of California San Diego

Brian T. Scott

University of California San Diego

Jian Wang

University of California San Diego

Anthony W. Ashton

University of Sydney

Jaladanki N. Rao

University of Maryland School of Medicine

Jason X.-J. Yuan

University of California San Diego

Jian-Ying Wang

University of Maryland School of Medicine

Ayako Makino ( $\nabla$ amakino@ucsd.edu )

University of California San Diego Health System https://orcid.org/0000-0003-1259-8604 
Original investigation

Keywords: Coronary microvascular disease, diabetic cardiovascular complications, gap junction, coronary flow velocity reserve

Posted Date: January 28th, 2021

DOI: https://doi.org/10.21203/rs.3.rs-154496/v1

License: (c) (1) This work is licensed under a Creative Commons Attribution 4.0 International License.

Read Full License 


\section{Abstract \\ Background}

Diabetic patients with coronary microvascular disease (CMD) exhibit higher cardiac mortality than patients without CMD. However, the molecular mechanism by which diabetes promotes CMD is poorly understood. RNA-binding protein HuR is a key regulator of mRNA stability and translation of many genes, and there is growing evidence showing the potential role of HuR in cardiovascular disease. In this study, we investigated the role of HuR and its target genes in the development of CMD in type 2 diabetic mice.

\section{Methods}

Type 2 diabetes was induced in male mice by a high-fat diet combined with a single injection of low-dose streptozotocin. We assessed coronary flow velocity reserve (CFVR, a determinant of coronary microvascular function) in vivo and isolated cardiac endothelial cells (CECs) from those mice for in vitro experiment. Coronary endothelial function was evaluated in the 3rd order of coronary arteries using a wire myograph. Human CECs from 4 control subjects and 4 diabetic patients were purchased from the company.

\section{Results}

Diabetic mice exhibited decreases in CFVR and capillary density in the left ventricle (LV). HuR protein levels in CECs were significantly lower in diabetic mice and diabetic patients than in the controls. Endothelial-specific HuR-KO mice also displayed significant reductions in CFVR and capillary density. By examining mRNA levels of 92 genes associated with endothelial function, we found that $H u R, C x 40$, and Nox4 levels were decreased in CECs from diabetic and HuR-KO mice in comparison to control mice. Cx40 protein level and HuR binding to $C \times 40$ mRNA were downregulated in CECs from diabetic mice, and $C \times 40$ KO mice exhibited decreased CFVR, attenuated endothelium-dependent relaxation, and reduced capillary density in the LV. Furthermore, endothelium-specific $C \times 40$ overexpression ameliorated endothelial functions by augmenting endothelium-dependent relaxation and increasing capillary density in the LV, and resulted in the improvement of CFVR in diabetic mice.

\section{Conclusions}

These data suggest that decreased HuR, a specific mRNA binding protein that downregulates gap junction protein $\mathrm{Cx} 40$ in CECs, plays an important role in the development of coronary microvascular disease in diabetes. Restoration of $\mathrm{Cx} 40$ expression and function is potentially a novel therapeutic strategy for diabetic cardiovascular complications. 


\section{Background}

Obstructive coronary artery disease (CAD) is the primary cause of cardiac ischemia and cardiac myocyte death; however, there is increasing evidence showing that non-obstructive CAD (also known as coronary microvascular disease [CMD]) is another risk factor for increased cardiac mortality [1-3]. In fact, stable patients who suffer from ischemia with CMD show a higher risk for major adverse cardiovascular events than patients with CAD [4]. However, patients with CMD are commonly treated with cardiovascular medication used for obstructive CAD, like anti-hypertension, angina therapy, or statin therapy [5]. Further understanding of the pathogenic mechanisms specifically involved in CMD is thus required to develop novel and unique therapeutic approaches for CMD and CMD-associated cardiac ischemia.

CMD is caused by coronary microvascular dysfunction, including microvascular rarefaction, small vascular remodeling, and attenuated vasodilatation in small coronary arteries (CAs) [1, 6-9]. Microvascular rarefaction is due to loss of existing capillary networks and attenuated regeneration of new capillaries. We and other investigators show that capillary density in the heart is decreased in diabetic animals and patients and that diabetic patients display reduced coronary flow reserve, a key determinant of coronary microvascular function [10-18]. In addition, diabetic patients with CMD show increased cardiac mortality compared to patients without CMD $[19,20]$. These studies suggest an urgent need to develop alternative treatments for diabetic patients with CMD. This study was designed to identify critical genes in diabetic cardiac endothelial cells (CECs) with altered expression levels that influence capillary density and ultimately induce CMD.

Human antigen R (HuR), a member of the embryonic lethal abnormal vision (ELAV) protein family, is an RNA-binding protein (RBP) that contains RNA recognition motifs with high affinity to AU-rich elements in the 3'-untranslated regions (3'-UTR) of transcripts [21]. Binding of HuR to mRNAs regulates the stability of mature mRNAs and mRNA decay [22]; therefore, HuR regulates mRNA expression levels of many genes via posttranscriptional modification directly or indirectly (e.g., by competing 3'-UTR with microRNA). Knockout (KO) of HuR in mice is embryonically lethal due to a placental defect [23]. $\beta$ cell-specific HuR$\mathrm{KO}$ increases reactive oxygen species (ROS) production and induces cell apoptosis [24]. HuR deletion in the intestinal epithelium leads to abnormal growth of the small intestine [25]. Neuron-specific HuR-KO mice exhibit motor deficiency phenotypes [26]. Smooth muscle-specific HuR-KO mice develop hypertension [27]. HuR-deletion in mouse cardiac myocytes (CMs), however, does not induce any apparent phenotype [28]. The HuR level is significantly decreased in the left ventricle (LV) of patients with heart failure [29] and aorta of rats with spontaneous hypertension [30]. In contrast, HuR expression is increased in cancer [31], diabetic nephropathy [32], and diabetic retinopathy [33]. HuR overexpression increases angiogenesis because HuR stabilizes VEGF-A mRNA and modifies angiogenic activity of endothelial cells (ECs) [34]. These data indicate that changes in HuR level contribute to the development of many diseases; it is, however, unclear whether HuR contributes to the development of CMD in diabetes.

In this study, we aimed to investigate coronary microvascular function in diabetic mice and EC-specific HuR-KO mice, identify the mRNAs with altered expression in CECs in diabetic mice and HuR-KO mice, and 


\section{Research Design And Methods}

\section{Materials}

Please find detailed material information in Additional File 1: Materials.

\section{Animals}

C57BL/6NHsd male mice were purchased from Envigo RMS Inc (IN, USA). Inducible T2D mice were generated by a single injection of streptozotocin (STZ, $75 \mathrm{mg}^{-\mathrm{kg}^{-1}}$, dissolved in citrate buffer, i.p.) at 6 weeks of age, and given a high-fat diet ( $60 \%$ kcal from fat, Envigo RMS Inc.) from the day of STZ injection. Sixteen weeks after diabetic induction, mice were randomly allocated to experimental groups and used before 26 weeks old ( 20 weeks after T2D induction). Oral glucose tolerance test (OGTT) and measurements of plasma cholesterol, $\mathrm{HDL}$, and triglyceride levels were performed as described $[18,35$, 36]. Male TALLYHO/Jng (TH) mice were purchased from The Jackson Laboratory (ME, USA) and bred in our animal facility. The TH mice are a polygenic T2D model, and male TH mice exhibit hyperglycemia, hyperinsulinemia, hyperlipidemia, and obesity [18]. We used male C57BL/ 6 mice as wild type (Wt) controls according to The Jackson Laboratory guideline. All mice were fed with a normal laboratory diet (13\% kcal from fat, Lab Diet, IN, USA). TH and Wt mice were used for experiments at the age of 16-20 weeks.

HuR floxed mice ( $\mathrm{HuR}^{\mathrm{fl} / \mathrm{fl}}$ ) were kindly provided by Dr. Jian-Ying Wang from the University of Maryland at Baltimore [25] and crossed with Tie2-Cre mice (The Jackson Laboratory) to generate endothelial cell (EC)specific HuR knockout (KO) mice (Tie2-HuR ${ }^{-/-}$mice, Fig. 3A). HuR ${ }^{\mathrm{wt} / \mathrm{wt}}$ mice were used as wild-type (Wt)

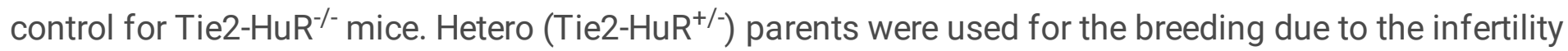
of homo (Tie2-HuR ${ }^{-/}$) parents. Genotype rates were: homozygous (17.4\%), heterozygous (29.9\%), and Wt (52.7\%) (Additional File 3: Fig. S1). Wt and Tie2-HuR ${ }^{-/-}$mice were used after 16 weeks old. Systemic Cx4O$\mathrm{KO}\left(\mathrm{C} \times 40^{-/}\right)$mice were kindly provided by Dr. Janis Burt from the UA [37], and C57BL/6J (background strain, The Jackson Laboratory) were used as a Wt control. They were used at 16 weeks old. EC-specific Cx40 overexpression ( $\mathrm{Cx} 40^{\mathrm{Tg}}$ ) mice were provided by Dr. Anthony Ashton from the University of Sydney [38]. This mouse strain carries the Tie2 (endothelium specific promoter)-driven wild type $\mathrm{Cx} 40$ gene with EGFP (Cx40-IRES-EGFP); therefore, the mice will constitutively express Cx40 in ECs. Heterozygous parents were identified by copy number measurement and used as a breeder. Mice without Tie2-CX40 gene were used as a Wt control of $\mathrm{C} \times 40^{\mathrm{Tg}}$ mice. These mice were bred in the animal facility of the UA and UCSD. Male mice were used for experiments between 22-26 weeks old (16-20 weeks after diabetic induction). The primer sequence information for genotyping is listed in Additional File 2: Table S1 and for real-time PCR in Additional File 2: Table S2. Heart dissection was performed under anesthesia with a mixture of ketamine (100 mg/kg, i.p.) and xylazine (5 mg/kg, i.p.), and all efforts were made to minimize pain. 
The age was matched between diabetic or transgenic mice and their control mice. Male mice were used in this study due to the difference in the onset of hyperglycemia and diabetic complications between male and female mice.

\section{Isolation of mouse cardiac endothelial cells (CECs)}

Mouse CECs were isolated using a method previously described [11, 12, 18, 35]. Briefly, after flushing blood from the heart, the heart was dissected, minced, and incubated with M199 containing $1 \mathrm{mg} / \mathrm{ml}$ collagenase II and $0.6 \mathrm{U} / \mathrm{ml}$ dispase II for $1 \mathrm{~h}$ at $37^{\circ} \mathrm{C}$. The digested material was collected and incubated with magnetic beads that were prepared as follows: Dynabeads ${ }^{\circledR}$ Sheep Anti-Rat IgG were incubated with rat anti-mouse CD31 monoclonal antibody $(1 \mu \mathrm{g} / \mathrm{ml})$ at $4^{\circ} \mathrm{C}$ overnight. The cell suspension was incubated with beads for $1 \mathrm{~h}$ at $4^{\circ} \mathrm{C}$, and then CECs were captured and isolated by the Dynal magnet (Thermo Fisher Scientific, MA, USA). The purity of the CEC population in cells isolated from hearts was tested by DilacLDL (Thermo-Fisher Scientific) uptake and Bandeiraea Simplicifolia lectin-FITC (BS-I, Sigma Aldrich, Inc. MO, USA) or CD144 staining (Additional File 3: Fig. S2). Efficient isolation yields approximately $10^{4}$ cells from one heart, with over $80 \%$ purity. Western blot and real-time PCR were conducted with freshly isolated CECs from mice. For the immunohistochemistry experiment, we cultured CECs after isolation, and experiments were performed within 5 days without passing the cells.

\section{Human CECs}

Human CECs from 4 control and 4 T2D patients were purchased from commercial suppliers (Additional File 1: Materials) and cultured in EC media composed of M199 supplemented with 10\% FBS, $100 \mathrm{U} / \mathrm{ml}$ penicillin, $100 \mu \mathrm{g} / \mathrm{ml}$ streptomycin, $20 \mu \mathrm{g} / \mathrm{ml}$ ECGS, and $16 \mathrm{U} / \mathrm{ml}$ heparin. All experiments were conducted before passage 10 .

\section{Isolation of mouse cardiac myocytes and aortic smooth muscle cells}

Mouse cardiac myocytes (CMs) were collected after removing ECs from the digested materials of the hearts. After removing ECs, the majority of cells in the digested material are cardiac myocytes; however, other types of cells (i.e., smooth muscle cells [SMCs] and fibroblasts) might be present in the samples at a very small percentage. The samples of aortic SMCs were obtained from an aorta after removing ECs by gently scrubbing the inner layer of the aortic lumen using a cotton tip.

\section{Coronary flow velocity reserve measurement}

Coronary flow velocity reserve (CFVR) was used to assess coronary microvascular function [18], instead of coronary flow reserve, because of the difficulty in precisely measuring coronary arterial diameter in mice [39]. Coronary blood flow velocity (CFV) was measured using a Vevo 2100 system (FUJIFILM Visual Sonics, Inc. Toronto, Canada. Additional File 3: Fig. S3). Mice were anesthetized with isoflurane and kept on the heating pad at $37^{\circ} \mathrm{C}$. The resting level of CFV was obtained at $1 \%$ isoflurane. CFVR was defined as maximal hyperemic CFV (induced by $2.5 \%$ isoflurane) divided by resting CFV ( $1 \%$ isoflurane) $[18,40]$. 
Each experiment was completed within $40 \mathrm{~min}$, and the heart rate was kept above $400 \mathrm{bpm}$. If the procedure took a longer time, or the heart rate was dropped lower than the criteria, the data was eliminated without analysis.

\section{Immunofluorescence experiment}

The evaluation of capillary density and EC apoptosis in the left ventricle (LV) were conducted as described previously $[11,12,18]$. Briefly, the heart was dissected, embedded in OCT compound, frozen in 2-methylbutane precooled with liquid nitrogen, and then kept at $-80^{\circ} \mathrm{C}$ until being sectioned. Sections (6 $\mu \mathrm{m}$ in thickness) were fixed in $4 \%$ formaldehyde for $5 \mathrm{~min}$, blocked with $5 \%$ BSA for $30 \mathrm{~min}$, and incubated with Bandeiraea Simplicifolia lectin-FITC (BS-I, Sigma Aldrich, Inc.) for 30 min. BS-I was used to probe the terminal $\beta$-galactosyl saccharides associated with endothelial cells on the surface of arterioles and venules as well as capillaries. Apoptotic cells were detected using a TUNEL assay (an in situ cell death detection kit, Roche).

After isolation of mouse CECs, cells were stained with HuR antibody and followed by anti-mouse Alexa488. The images were captured with a Nikon Eclipse Ti-E 3D Deconvolution microscope (Nikon Corp. Tokyo, Japan) with a 20x objective lens (for EC apoptosis and capillary density) or 60x objective lens (for HuR staining) in a blinded fashion. The fluorescence intensities were calculated using ImageProPLUS 7.0 software (Media Cybernetics Inc. MD, USA).

\section{Western blot analysis}

Protein levels were analyzed using SDS-PAGE separation and electrophoretic transfer to nitrocellulose membranes. Primary antibodies used in this study are listed in Additional File 1: Materials.

\section{Real-time PCR}

mRNA from mouse CECs was isolated using a miRNeasy Mini Kit (QIAGEN, CA, USA), and cDNA was made by RT ${ }^{2}$ First Strand Kit (QIAGEN). We chose 92 genes (including Actb and Gapdh) that are highly expressed in ECs and play crucial roles in endothelial functions for analysis by real-time PCR, including a) endothelium-derived relaxing factors and their regulators; b) modifiers of cytosolic $\mathrm{Ca}^{2+}$ concentration $\left(\left[\mathrm{Ca}^{2+}\right]\right)$, mitochondrial $\left[\mathrm{Ca}^{2+}\right]$, and endoplasmic reticulum $\left[\mathrm{Ca}^{2+}\right]$; and c) regulators of EC proliferation/migration/apoptosis (see Additional File 2: Table S3 for the gene list). The custom PCR plates were made by QIAGEN based on the selected genes (SABIO Number CAPA38128-6:CLAM25240). One 384-well plate includes quadruplicate wells for one gene (for the gene of interest and internal control) and replicates genomic DNA controls, reverse-transcription controls, and positive PCR controls. Primer sets used for the PCR plate are authenticated by the company. Real-time PCR was conducted using the CFX384 Touch Real-Time PCR Detection System (Bio-Rad Laboratories, CA, USA). GAPDH was used as an internal control. The transcript levels of the Gene of Interest were quantified according to the cycle threshold $(\Delta \mathrm{Ct})$ method. $\mathrm{Ct}$ values $>35$ were not included in the analysis and were considered as negative. Note that the primer set for Elav/1 (HuR) on the plate (Product \# PPM30921A, QIAGEN) detects 
exon 5, not exon 2; therefore, real-time PCR was repeated using an exon 2-specific primer (Additional File 2: Table S2).

\section{Ribonucleoprotein immunoprecipitation (RIP)}

To assess the association of endogenous HuR protein with endogenous $C \times 40$ mRNA, immunoprecipitation (IP) of ribonucleoprotein complexes was performed as previously described [25] (Additional File 3: Fig. S4). Mouse CECs were isolated and lysed with lysate buffer $(100 \mathrm{mM} \mathrm{KCl}, 5 \mathrm{mM}$ $\mathrm{MgCl}_{2}, 10 \mathrm{mM}$ HEPES [pH7.0], 0.5\% Igepal, $1 \mathrm{mM}$ DTT, 1\% protease inhibitor cocktail, $1 \%$ phosphatase inhibitor cocktail, $100 \mathrm{U} / \mathrm{ml}$ in RNase free water). Prior to RIP, the IP matrix was conjugated with HuR antibody or IgG, and cell lysate was incubated with IP matrix overnight. RNA in IP materials was used for reverse transcription, followed by real-time PCR analysis (Fig. 4). The data of $C \times 40$ mRNA bound to HuR protein was normalized by $C \times 40$ mRNA bound to IgG.

\section{Isometric tension measurement in coronary arterial ring}

Isometric tension measurement in coronary arteries (CAs) was performed as described previously $[11,35$, 36]. Briefly, third-order small CAs were dissected from the hearts and then cut into 1-mm segments. The CA rings were mounted on a myograph (DMT-USA, Inc. MI, USA) using thin stainless wires $(20 \mu \mathrm{m}$ in diameter), and the resting tension was set at $100 \mathrm{mg}$. CAs were allowed to equilibrate for $45 \mathrm{~min}$ with intermittent washes every 15 min. After equilibration, each CA ring was contracted by treatment with $\mathrm{PGF}_{2 \mathrm{a}}$ to generate a similar contraction level in all groups. The concentration of $\mathrm{PGF}_{2 \mathrm{a}}$ used for precontraction was $5.34 \pm 0.19$ in Wt and $5.63 \pm 0.16$ in $\mathrm{Cx} 40^{-/-}$mice (shown in $-\log \mathrm{M}$ ). The diameter of the vessels was $134.6 \pm 7.1 \mu \mathrm{m}$ in Wt and $136.1 \pm 5.4 \mu \mathrm{m}$ in $\mathrm{Cx} 40^{-/-}$mice. There was no significant difference in either $\mathrm{PGF}_{2 a}$ concentration or vessel diameter between $\mathrm{Wt}$ and $\mathrm{Cx} 40^{-/-}$mice. Acetylcholine (ACh) or sodium nitroprusside (SNP, an NO donor) was administrated in a dose-dependent manner (1 $\mathrm{nmol} / \mathrm{l}$ to $100 \mu \mathrm{mol} / \mathrm{l})$. The degree of relaxation was shown as a percent of PGF2a-induced contraction.

\section{Tube formation assay in human CECs}

We used $\mathrm{Cx} 40$ adenovirus (Cx40-Adv) to overexpress the $\mathrm{Cx} 40$ gene [11]. HuR downregulation was achieved by HuR siRNA transfection (Santa Cruz Biotechnology Inc. Dallas, TX). Human control CECs ( $10^{5}$ cells) were seeded on a $3 \mathrm{~cm}$ plate, and Control- or Cx40-Adv was added to the cells at the titer of $100 \mathrm{pfu} / \mathrm{cell}$ on the following day. Twenty-four hours later, the viruses were washed, and cells were transfected with control siRNA or HuR siRNA at $100 \mathrm{nM}$ using lipofectamine 3000 reagent (Thermo Fisher Scientific). Specific protein knockdown was verified with Western blotting 48 hours after transfection (Additional File 3: Fig. S5). For tube formation assay [18], cells were detached, and $4 \times 10^{4}$ cells were seeded on the Matrigel-coated 4-well chamber. Twenty-four hours after plating cells, 4 microscopic fields, selected at random, were photographed using an EVOS FL Auto Cell Imaging System with 4x objective lens (Thermo Fisher Scientific) in a blinded fashion. Meshes number, total meshes area, junction number, 
segments number, and total segments length were analyzed using Angiogenesis Analyzer in NIH ImageJ $1.51 \mathrm{k}$ software.

\section{Cytosolic ROS measurement in human CECs}

HuR and Cx40 were downregulated using HuR siRNA or Cx40 siRNA, respectively (Santa Cruz Biotechnology Inc.). Human control CECs $\left(2 \times 10^{4}\right.$ cells) were seeded on a 4-well glass chamber and then transfected with control-, HuR- or Cx40-siRNA at $100 \mathrm{nM}$ using lipofectamine 3000 reagent. Cytosolic ROS was detected using the fluorescent probe dihydroethidium (DHE). Cells were preloaded with $50 \mu \mathrm{mol} / \mathrm{I}$ DHE for 30 min before capturing images. Cytosolic DHE exhibits blue fluorescence; once it is oxidized by ROS, it illuminates red (ethidium bromide [EB]). The images were captured with a Nikon Eclipse Ti-E 3D Deconvolution microscope with a $60 x$ objective lens in a blinded fashion. The fluorescence intensity was calculated using ImagePro-PLUS 7.0 software. The background fluorescence intensity was subtracted from the cell intensity. The index of cytosolic ROS concentration is described as a ratio of EB and DHE.

\section{Statistics}

We conducted data analysis in a blinded fashion wherever possible and set proper controls for every experimental plan. The mouse numbers and independent experiment numbers are described in the figure legends. Statistical analysis was performed using GraphPad Prism 9 (La Jolla, CA, USA). Data are presented as mean \pm SEM. After the data passed a normality test (Kolmogorov-Smirnov), the two-tailed Student's $t$-test was used for comparisons of two groups, and one-way ANOVA was used for multiple comparisons. If the data did not pass the normality test, a non-parametric test (Mann-Whitney for two groups, Kruskal-Wallis for multiple comparisons) was used. Bonferroni's multiple comparisons test was used as a post hoc test for one-way ANOVA and Dunn's test for the Kruskal-Wallis test. Statistical comparison between dose-response curves was made by two-way ANOVA with Bonferroni post hoc test. Differences were considered to be statistically significant when $P<0.05$.

\section{Results}

\section{Coronary microvascular dysfunction in diabetic mice}

We used type 2 diabetic (T2D) model mouse generated by high-fat diet feeding and a single low-dose injection of STZ. Our diabetic mice exhibited increased body weight, abnormal glucose tolerance, and dyslipidemia (Fig. 1, Table 1, and Table 2). Coronary flow velocity reserve (CFVR) was measured as a determinant of coronary microvascular function (Additional File 3: Fig. S3) [18, 39, 40]. Decreased CFVR indicates that mice are suffering from CMD and prone to ischemic heart disease [18]. We found that CFVR was significantly reduced in diabetic mice compared to control (Fig. 1C). In the LV, diabetic mice showed significantly lower capillary density (Fig. 1D) and higher EC apoptosis (Additional File 3: Fig. S6) than control mice. These results indicate that coronary microvascular function, due potentially to reduced capillary density, is significantly attenuated in mice with experimental diabetes. 


\section{Decreased HuR protein level in CECs isolated from diabetic mice and patients}

Freshly isolated mouse CECs were used to detect HuR levels in control and diabetic mice. HuR levels were significantly decreased in CECs from diabetic mice compared to those from control mice, as determined by Western blot (Fig. 2A) and immunofluorescence study (Fig. 2B). In line with inducible T2D mouse data, CECs from spontaneous T2D mouse model (Tallyho [TH] mice) and CECs from diabetic patients exhibit a significant decrease in HuR protein level compared to their controls (Fig. 2C-D). On the other hand, HuR levels in cardiac cells (remain heart cells after depletion of ECs) and aortic SMCs were not different between control and diabetic mice (Additional File 3: Fig. S7). Taken together, HuR protein is selectively downregulated in CECs in diabetic mice, and endothelial downregulation of HuR is a potential contributor to reduced capillary density in the heart and decreased coronary microvascular function in diabetes.

\section{Endothelium-specific HuR knockout (Tie2-HuR ${ }^{-/}$) mice develop CMD}

To investigate the role of HuR in the development of CMD, we generated EC-specific HuR-KO mice (Tie2$\mathrm{HuR}^{-/}$) by crossing HuR exon-2 floxed mice ( $\mathrm{HuR}^{\mathrm{fl} / \mathrm{fl}}$ ) with Tie2-driven Cre-overexpressing mice (Fig. 3A). Figure 3B shows the typical genotyping result from the tail samples of wild-type (Wt), HuR ${ }^{\mathrm{fl} / \mathrm{fl}}, \mathrm{Tie} 2-\mathrm{HuR}^{-/+}$, and Tie2-HuR ${ }^{-/-}$mice. Next, we examined HuR gene expression in CECs isolated from Wt and Tie2-HuR ${ }^{-/-}$ mice. HuR deletion from ECs abolished HuR mRNA expression (Fig. 3C) and HuR protein (Fig. 3D) in mouse CECs, whereas HuR deletion did not alter HuR levels in CMs (Fig. 3E). There is no difference in body weight, blood glucose, and mean arterial pressure (MAP) between Wt and Tie2-HuR ${ }^{-/-}$mice (Table 2). However, Tie2-HuR ${ }^{-/-}$mice displayed decreased CFVR (Fig. 3F) and capillary density (Fig. 3G), and increased apoptotic ECs compared to Wt mice (Additional File 3: Fig. S6). We found that there was no significant difference in apoptotic cell number in other cell types (total apoptotic cells \# - apoptotic endothelial cell \#) between Wt mice and Tie2-HuR ${ }^{-/-}$mice (Wt, $2.4 \pm 0.4 \mathrm{NA} / \mathrm{mm}^{2}$; Tie2-HuR ${ }^{-/}, 2.9 \pm 0.5$ $\mathrm{NA} / \mathrm{mm}^{2} ; \mathrm{n}_{\text {mice }}=5$ per group), indicating that cell apoptosis induced by HuR deletion was confined to CECs. These data provide strong evidence that EC-specific deletion of HuR induces the reduction of capillary density and ultimately attenuates coronary microvascular function.

\section{Target genes with altered expression in CECs from diabetic and Tie2-HuR ${ }^{-/-}$mice}

To define the target genes altered by HuR deletion and by diabetes, we conducted the real-time PCR on 92 genes (the gene list is shown in Additional File 2: Table S3) and compared the mRNA levels of these genes between control and diabetic mice (Additional File 2: Table S4) and between Wt and Tie2-HuR ${ }^{-1-}$ mice (Additional File 2: Table S5). The genes altered by diabetes and/or HuR deletion are summarized in a Venn Diagram (Fig. 4A). We chose the 92 genes that are expressed in ECs and play crucial roles in endothelial functions, such as a) endothelium-derived relaxing factors and their regulators; $b$ ) modifiers of cytosolic $\left[\mathrm{Ca}^{2+}\right]$, mitochondrial $\left[\mathrm{Ca}^{2+}\right]$, and endoplasmic reticulum $\left[\mathrm{Ca}^{2+}\right]$; and c) regulators of EC proliferation, migration, and apoptosis. The expression levels of 3 genes: Elav1 (HuR), Gja5 (connexin40, Cx40), and nicotinamide adenine dinucleotide phosphate reduced oxidases 4 (Nox4) were significantly 
decreased in CECs from diabetic mice and in CECs from Tie2-HuR ${ }^{-/-}$mice compared to their controls. These results demonstrate that a selective group of genes (i.e., HuR, Cx40, and Nox4) is concomitantly downregulated in mice with diabetes and mice genetically deleted endothelial HuR. The next set of experiments was designed to examine whether downregulated HuR in diabetic mice may directly regulate Cx40, an important gap junction protein required for normal EC function, to decrease coronary microvascular function.

\section{Downregulated Cx40 level and decreased Cx40 mRNA binding to HuR protein in CECs of diabetic mice}

We first confirmed that Cx40 protein level was downregulated in CECs from diabetic mice (Fig. 4B) and Tie2-HuR ${ }^{-/-}$mice (Fig. 4C) compared to their controls. Next, we performed ribonucleoprotein immunoprecipitation to examine the binding of $C \times 40 \mathrm{mRNA}$ to HuR protein and found that $C \times 40 \mathrm{mRNA}$ binding to HuR protein was significantly lower in CECs from diabetic mice than in CECs from control mice (Fig. 4D). Taken together, downregulated $\mathrm{Cx} 40$ in diabetic EC is potentially due to reduced HuR level and decreased HuR binding to $\mathrm{Cx} 40$ in diabetic mice.

\section{Deletion of Cx40 decreases CFVR by reducing capillary density}

Since HuR downregulation results in decreased $\mathrm{Cx} 40$ protein level, we examined the role of $\mathrm{Cx} 40$ in the development of CMD. Cx40 is a component of gap junction that acts as a tunnel for small molecules ( $<1$ $\mathrm{kDa}$ ) and electrical propagation during endothelium-derived hyperpolarization (EDH)-dependent vascular relaxation. There was no difference in body weight between Wt and $\mathrm{C} \times 40^{-1-}$ mice; however, $\mathrm{Cx} 40^{-/-}$mice exhibited a slight, but statistically significant increase in plasma glucose level and MAP (Table 2). Figure $4 \mathrm{E}$ demonstrated that $\mathrm{C} \times 40$ protein level was diminished in $\mathrm{CECs}$ of $\mathrm{C} \times 40^{-/-}$mice. Endothelium-dependent relaxation was assessed by acetylcholine (ACh)-induced relaxation, and EDH-dependent relaxation was evaluated by ACh-induced relaxation in the presence of L-NAME (an eNOS inhibitor) and indomethacin (a cyclooxygenase inhibitor). We confirmed that endothelium-dependent relaxation (Fig. 4F) and EDHdependent relaxation (Fig. 4G), but not EC-independent relaxation (Fig. 4H), were significantly attenuated in CAs isolated from $\mathrm{C} \times 40^{-/-}$mice compared to Wt mice. Those data indicate that deletion of $\mathrm{C} \times 40$ sufficiently inhibited gap junction function. Importantly, $\mathrm{Cx} 40^{-/-}$mice exhibited a significant decrease in CFVR (Fig. 4I) and capillary density (Fig. 4J), and an increase in EC apoptosis (Additional File 3: Fig. S6) compared to Wt. These results indicate that $\mathrm{Cx} 40$, which is directly regulated by HuR, is required for maintaining normal coronary endothelial function.

\section{Inhibition of HuR attenuates tube formation in control CECs, and overexpression of CX40 increases tube formation in HuR-reduced CECs}

To examine how HuR deletion and $C x 40$ overexpression alter angiogenic capability of ECs, we conducted an ex vivo tube formation assay in human CECs. Cx40 was overexpressed using Cx40-adenovirus (Adv), and HuR was inhibited by HuR siRNA transfection in human CECs (Additional File 3: Fig. S5). Figure 5 demonstrates that HuR inhibition in control CECs significantly reduced tube formation, suggesting that 
HuR regulates endothelial angiogenic capability. $C \times 40$ overexpression in control CEC did not affect angiogenic capability; however, $C x 40$ overexpression in HuR-inhibited CECs slightly, but significantly, increased tube formation. Taken together, the decreased Cx40 due to HuR downregulation in CECs contributes to inhibiting EC-driven angiogenesis, reducing capillary density, and ultimately attenuating coronary microvascular function.

\section{Overexpression of Cx40 in diabetic mice improves coronary microvascular function}

Type 2 diabetes was induced in Wt mice and EC-specific $C x 40$-overexpressing mice [38]. The mice were used for the experiments 16 weeks after diabetic induction. Under diabetic conditions, $C \times 40$ transgenic mice demonstrated increased Cx40 protein levels in CECs compared to Wt (Fig. 6A). Cx40 overexpression did not alter body weight (Fig. 6B) or glucose tolerance (Fig. 6C) in diabetic mice but decreased plasma glucose level at non-fasting conditions (Table 2). Endothelium-dependent relaxation (Fig. 6D), but not smooth muscle-dependent relaxation (Fig. 6E), was significantly augmented by $\mathrm{Cx} 40$ overexpression in CAs of diabetic mice. Furthermore, $C \times 40$ overexpression significantly increased capillary density (Fig. 6F) and CFVR (Fig. 6G) in diabetic mice. We here provide strong evidence that overexpression of $\mathrm{Cx} 40$ is sufficient to restore EC-dependent vasodilation, capillary density, and CFVR in diabetic mice. These observations suggest that increasing $\mathrm{C} x 40$ expression and/or function is a potential strategy for treating CMD in diabetes in which HuR level is downregulated.

\section{Discussion}

Clinical data indicate that diabetic patients with $\operatorname{CMD}$ exhibit high cardiac mortality $[19,20]$; however, the molecular mechanisms by which diabetes leads to CMD is poorly understood. To investigate microvascular function in diabetes, we used an inducible T2D mouse model generated by administrating a single injection of low-dose STZ and feeding a high-fat diet. This mouse model has given us reproducible data with hyperglycemia and hyperinsulinemia [35, 36]. T2D mice not only exhibited increased body weight and abnormal glucose tolerance, but also suffered from dyslipidemia (Figs. 1A, and 1B, and Tables 1 and 2). However, lipid plaque formation has never been detected in this model. Therefore, the reduction of CFVR (Fig. 1C) is due solely to coronary microvascular dysfunction, and decreased CFVR indicates that mice suffer from CMD. In line with the result from inducible T2D mice, TH mice (spontaneous T2D mice) exhibited reduced CFVR [18] without detectable plaque formation, suggesting that chronic hyperglycemia is the risk factor of CMD. Since capillary density positively correlates with coronary flow reserve [8,41,42], decreased capillary density in the heart could be a cause of reduced CFVR. Figure 1D demonstrates that T2D mice displayed decreased capillary density in the LV. Capillary density can be reduced by 1 ) augmented endothelial cell apoptosis, 2) attenuated cell migration and/or proliferation of neighboring mature ECs, and/or 3) reduced mobilization of circulating endothelial progenitor cells (EPCS) in sites of the vascular wall where ECs are damaged and/or lost. We and other investigators demonstrated that CECs are apoptotic in diabetes [12, 18, 43, 44] (Additional File 3: S6) and characterized by a diminished ability to migrate and proliferate in diabetes $[18,45]$. The number of EPCs is also decreased, and the function of EPCs is attenuated in diabetic patients and diabetic animal models 
$[46,47]$. This study was designed to identify the key genes that influence capillary density and ultimately change microvascular function in the diabetic heart.

Like other RNA-binding proteins, HuR binds to many RNAs and changes their fates. The data from systemic and tissue-specific deletion of HuR gene indicate that HuR plays a critical role in embryonic development and the regulation of physiological function [23-26]. Therefore, it was natural to hypothesize that an abnormal level of HuR may be involved in the development or progression of cardiovascular disease. The conclusive data came from cancer research at first; HuR expression is increased with cancer and aids in the progression of angiogenesis in tumor tissue [31]. However, the contribution of HuR to other diseases is still controversial. Zhou et al. demonstrated that HuR protein level was significantly reduced in the heart from the patients with heart failure compared to control patients [29]. They also showed that myocardial infarction (MI) decreased HuR protein level in mouse hearts, and overexpression of HuR by AAV-HuR injection reduced infarct size and improved cardiac function [29]. On the other hand, Krishnamurthy et al. found that HuR level was increased after MI in mice, and downregulation of HuR by HuR-shRNA lentivirus injection restored cardiac function [48]. Unfortunately, we could not find the reason for the discrepancy between these studies. Recent reports demonstrate that HuR upregulation is implicated in the development of atherosclerosis $[49,50]$ and diabetic nephropathy [51]. We found that HuR level was significantly decreased in CECs from diabetic mice compared to control mice (Figs. 2A, 2B). This phenomenon was also observed in CECs from a spontaneous T2D mouse model, TH mice (Fig. 2C), and CECs from diabetic patients (Fig. 2D). Tie2-HuR ${ }^{-/-}$mice exhibited similar microvascular functions to T2D mice (reduced CFVR, decreased capillary density, and increased EC apoptosis in the LV compared to Wt, see Fig. 3 and Additional File 3: Fig. S6), suggesting that decreased HuR expression in CECs is one of the leading causes of CMD in diabetes.

Some might think that it would be essential to examine the effect of $H u R$ overexpression on EC function in diabetic mice, and we agree. However, we encountered a problem when overexpressing HuR in CECs. In ex vivo studies, we found that the working concentration of HuR overexpression is very narrow.

Overexpression of HuR easily killed CECs, and we had a very difficult time controlling HuR levels during the experiment. This implies that HuR may not only interact with mRNAs that are important for EC angiogenesis, but also bind to mRNAs that regulate cell death. Therefore, we decided to examine the target genes of HuR, which are also involved in CMD in diabetes. We examined 92 (Additional File 2: Table S3) genes by real-time PCR using a PCR plate custom-made by QIAGEN. We are aware that there are other genes which are not included in the plate but are also important for EC function. We did not use a microarray or RNAseq in this study because: 1 ) these experiments would require more animals to obtain a sufficient amount of mRNA, and 2) they would provide an overwhelming amount of information for the studies at the time. We believe that real-time PCR with 92 genes still gave us sufficient information to move to the next step. Interestingly, we found that only 3 genes out of 92 were altered in CECs by HuR deletion and diabetes: HuR, Cx40, and Nox4 (Fig. 4 and Additional File 2: Table S4 and S5). Cx40 protein levels were significantly decreased in diabetes and Tie2-HuR ${ }^{-/-}$mice compared to those controls and HuR-bound $C \times 40$ mRNA was significantly lower in diabetes than in control (Figs. 4B-4D). These data 
indicate that $\mathrm{Cx} 40$ could be a potential target of HuR. It is important to note that we examined the protein level of Nox4 and found that Nox4 protein level was not altered in CECs of diabetic mice compared to the control (Control, $1.01 \pm 0.06$; Diabetic, $1.16 \pm 0.32$. $\mathrm{N}_{\text {mice }}=7$ per group. $P=0.65$ ). Therefore, we did not conduct a further experiment to examine the role of Nox4 in this study. We were indeed surprised to see that only 3 genes were shared in diabetic and Tie2-HuR ${ }^{-/-}$mice after screening genes in an unbiased way. These results suggested that HuR overexpression in diabetic mice may not be ideal since it would potentially lead to unnecessary alterations in many other genes besides Cx40. Thus, we believe overexpression of $\mathrm{Cx} 40$, a downstream HuR-sensitive gene, in diabetes could be a safer and better option to treat diabetic cardiovascular complications than overexpression of modification of HuR.

Cx40 is a major gap junction protein in ECs, and decreased gap junction activity due to reduced $\mathrm{Cx} 40$ expression attenuates EDH [52] and endothelial migration [53]. We and other investigators demonstrated that ECs in type 1 diabetic mice exhibited a significant decrease in Cx40 protein level [11,54]. However, there is no report examining the role of Cx40 in CECs of T2D mice to the best of our knowledge. The results from Fig. 4 suggest that HuR regulates $C x 40$ gene expression in CECs and decreased HuR protein level and HuR-binding to $C x 40$ mRNA are, at least in part, the causes for downregulated $\mathrm{Cx} 40$ expression in CECs in diabetes. Therefore, we obtained $\mathrm{CX}_{4} \mathrm{O}^{-/-}$mice [37] (Fig. 4E) to examine whether mice without Cx40 exhibit similar coronary microvascular function shown in diabetes. First, we examined EDHdependent relaxation in 3rd order of CAs to show the functional change of gap junction by $\mathrm{Cx} 40$ deletion. EDH was abolished by $C \times 40$ deletion in CAs (Fig. 4G) without any change in smooth muscle-dependent relaxation (Fig. $4 \mathrm{H}$ ), suggesting that $C x 40$ deletion is functionally working. Next, we examined coronary microvascular function and found that CFVR was significantly reduced in $\mathrm{C} \times 40^{-/-}$mice (Fig. 4I) accompanied by decreased capillary density and increased EC apoptosis (Figs. 4J and Additional File 3: Fig. S6). This is the first report to demonstrate that the loss of $C \times 40$ leads to CMD. We, therefore, hypothesized that the CMD seen in T2D mice might result from decreased Cx40 expression in CECs due to downregulated HuR expression.

It has been known for decades that coronary endothelial dysfunction is implicated in the development of obstructive CAD. However, the Women's Ischemia Syndrome Evaluation (WISE) study shed light on endothelial dysfunction in patients with non-obstructive CAD (CMD) in 2004. Their data suggest that the decrease in coronary microvascular function predicts adverse cardiovascular outcomes independent of CAD severity [55]. In addition, the treatment with ranolazine (a late sodium current inhibitor that is commonly used for obstructive CAD) does not show any beneficial effect on ischemia in patients with CMD [56]. These reports emphasize the necessity to develop new drugs specific for patients with CMD. We believe that $\mathrm{CX} 40$ is an excellent therapeutic target for CMD based on the following reasons: 1 ) there are more myoendothelial gap junctions that are composed of connexins (Cxs) in smaller resistant vessels than in large vessels [57-59], suggesting that $C \times 40$ upregulation could be more effective in small vessels; 2) Cx40 is predominantly expressed in ECs $[57,60]$; therefore, increased Cx40 expression and activity lead to a specific effect on EC function; and 3) overexpression of $\mathrm{Cx} 40$ does not lead to abnormal angiogenesis as shown in tumor tissues [61]. We demonstrate here that overexpression of Cx40 in ECs 
augments endothelium-dependent relaxation, increases capillary density, and results in improved CFVR in diabetic mice (Fig. 6). These results provide strong evidence that overexpression of $\mathrm{Cx} 40$ is a useful therapeutic strategy for CMD in diabetes.

Overexpression of Cx40 augmented angiogenesis in HuR-deficient CECs ex vivo (Fig. 5) and in vivo (Fig. 6E). Other investigators also show that $\mathrm{Cx} 40$ positively regulates cell migration and angiogenesis [53]; however, the detailed mechanisms of how exactly $\mathrm{Cx} 40$ enhances angiogenesis is still unknown. It has been reported that $C x 43$ overexpression increases $[62,63]$ or decreases $[64,65]$ angiogenesis or cell migration independently of gap junction activity. The deletion of Cx37 promotes angiogenesis [66]. These data suggest that the effect of $\mathrm{Cxs}$ on cell migration and angiogenesis seems to be different among the subtypes of $\mathrm{Cxs}$ and that enhanced EC angiogenesis by $\mathrm{Cx} 40$ overexpression might be not only due to increased gap junction activity, but also due to unknown mechanisms through $C \times 40$ overexpression. It has been reported that $\mathrm{Cx} 43$ regulates the expression of other genes [67]; therefore, it is possible that $\mathrm{Cx} 40$ can also regulate the expression of other genes.

HuR or $C x 40$ deletion in ECs led to endothelial apoptosis (Additional File 3: Fig. S6). In this study, we focused on angiogenic capability of ECs (Fig. 5) rather than endothelial apoptosis. However, increased cell apoptosis by HuR or $C \times 40$ deletion would contribute to decreased capillary density in the heart. Excess production of ROS is one of the leading causes of cell apoptosis. We previously reported that ROS formation in CECs was considerably increased in diabetes [12, 35, 68, 69]. Additional File 3: Fig. S8 demonstrates that the deletion of HuR or $C \times 40$ gene increased cytosolic ROS formation in human CECs. Excess ROS production by HuR inhibition was sort of expected since HuR deletion significantly downregulates Opa 1 expression (Fig. 4 and Additional File 2: Table S5). Opa1 is a mitochondrial fusion protein, and reduced mitochondrial fusion (or increased mitochondrial fission) increases mitochondrial ROS formation, followed by the rise of cytosolic ROS concentration [70]. Increased ROS generation by Cx40 inhibition surprised us and would require further experiments to identify the molecular mechanisms. Other investigators have also investigated the potential mechanisms in which the inhibition of HuR leads to cell apoptosis. HuR binds to Mdm2, a primary negative regulator of p53; therefore, deletion of HuR increases p53 and leads to cell apoptosis [71]. Inhibition of HuR also increases caspase 3 expression [26] and other proapoptotic factors [71] that ultimately induces cell apoptosis. We have reported that p53 is one of major causes of coronary endothelial apoptosis in diabetes, and inhibition of p53 improves coronary microvascular function [18]. It has to be noted that the mechanisms to induced endothelial cell apoptosis in Tie2-HuR ${ }^{-/-}$and diabetic mice might be the same or different; therefore, it requires additional experiments to identify detailed molecular mechanisms in which HuR deletion- and hyperglycemiainduced endothelial-apoptosis in the heart.

We found that $\mathrm{C} \times 40^{-/-}$mice exhibited a significant increase in plasma glucose level, and $C \times 40$ overexpression in diabetes displayed a slight but significant decrease in plasma glucose level (Table 2). In the endocrine system, $\mathrm{Cx} 40$ is well known to regulate the function of renin-producing cells in the kidneys. Therefore, the increase in blood pressure by $C \times 40$ deletion (Table 2) might be partly led by increased renin secretion [72]. However, there is no report showing that Cx40 contributes to insulin 
secretion and/or glucose tolerance. Cx36 is expressed in $\beta$-cells, and $C \times 36-K O$ mice develop glucose intolerance via attenuation of glucose-stimulated insulin secretion from the $\beta$-cells [73]. Although $\mathrm{Cx} 40$ is not expressed in $\beta$-cells, there may be mechanisms by which $\mathrm{Cx} 40$ regulates plasma glucose level (e.g., altered infiltration of inflammatory cells in adipose tissues). We will further investigate this unique phenomenon in future studies.

\section{Conclusions}

This study demonstrates for the first time that diabetes leads to downregulation of HuR, an RNA-binding protein, which subsequently decreases expression of $\mathrm{Cx} 40$, a gap junction channel protein, in cardiac ECs, and attenuates coronary microvascular function in diabetes. Overexpression of $\mathrm{Cx} 40$ increases capillary density and restores coronary microvascular function determined by CFVR in diabetes. These data indicate that $\mathrm{Cx} 40$ is a promising therapeutic target for developing novel and unique treatment for $\mathrm{CMD}$ in diabetic patients.

\section{Abbreviations}

ACh: acetylcholine

Adv: adenovirus

BS-I Bandeiraea Simplicifolia lectin

CA: coronary artery

CAD: coronary artery disease

CEC: cardiac endothelial cell

CFVR: coronary flow velocity reserve

CMD: coronary microvascular disease

Cx: connexin

Cx40 Tg: Cx40 overexpression mice (endothelium-specific)

Cx40 ${ }^{-/}$: connexin 40 knockout mice

ELAV: embryonic lethal abnormal vision

EC: endothelial cell

ECGS: endothelial cell growth supplement 
EDH: endothelium-derived hyperpolarization

EPC: endothelial progenitor cells

HuR: human antigen $\mathrm{R}$

$H_{\mathrm{R}} \mathrm{R}^{\mathrm{f} / \mathrm{fl}:}$ HuR floxed mice

HuR $^{-/-}$HuR knockout mice

KO: knockout

LV: left ventricle

OGTT: oral glucose tolerance test

RBP: RNA-binding protein

RIP: ribonucleoprotein immunoprecipitation

ROS: reactive oxygen species

SNP sodium nitroprusside

STZ: streptozotocin

TH: TALLYHO/Jng

3'-UTR: 3'-untranslated regions

Wt: wild type

\section{Declarations}

\section{Acknowledgments}

We thank Dr. Janis Burt at the University of Arizona for providing the mice lacking $C x 40$ gene for this study.

\section{Authors' contributions}

R.S. and J.C. conducted the experiments, analyzed the data, and drafted and reviewed the manuscript. A.T., L.G., R.G., M.W., Y.L., J.M., and J.R. conducted the experiments and reviewed the manuscript. B.S., J.W., A.A., J.Y., and J.W. reviewed and edited the manuscript. A.M. conceived the project, designed the experiments, analyzed the data, and reviewed and edited the manuscript. 


\section{Funding}

This work was supported by grants from the National Heart, Lung, and Blood Institute of the National Institutes of Health (HL142214 and HL146764 to A. Makino).

\section{Availability of data and materials}

Not applicable.

\section{Ethics approval and consent to participate}

All experimental protocols used in this study were approved by the Institutional Animal Care and Use Committee (IACUC) at The University of Arizona (UA) and the University of California, San Diego (UCSD) and conformed to the Guide for the Care and Use of Laboratory Animals published by the National Institutes of Health. The universities have been certified by Public Health Service with Animal Welfare Assurance number A3248-01 (UA) and A3033-01 (UCSD); the approved IACUC protocol numbers for this study are 14-520 (at UA) and S18185 (at UCSD). The laboratory personnel who conducted experiments took all training required for animal handling and were certified by the IACUC.

\section{Consent for publications}

Not applicable.

\section{Competing interests}

The authors declare that they have no competing interests.

\section{Author details}

${ }^{1}$ Department of Physiology, The University of Arizona, Tucson, Arizona, USA

${ }^{2}$ Department of Medicine, University of California, San Diego, La Jolla, California, USA

${ }^{3}$ Department of Cardiology, Xijing Hospital, Fourth Military Medical University, Shaanxi, China

${ }^{4}$ State Key Laboratory of Respiratory Disease, Guangzhou Institute of Respiratory Disease, The First Affiliated Hospital of Guangzhou Medical University, Guangzhou, China

${ }^{5}$ Division of Perinatal Research, Kolling Institute of Medical Research, University of Sydney, New South Wales, Australia

${ }^{6}$ Department of Surgery, University of Maryland School of Medicine, Baltimore, Maryland, USA

\section{References}


1. Spoladore R, Fisicaro A, Faccini A, Camici PG: Coronary microvascular dysfunction in primary cardiomyopathies. Heart 2014, 100(10):806-813.

2. Petersen JW, Pepine CJ: Microvascular coronary dysfunction and ischemic heart disease: where are we in 2014? Trends Cardiovasc Med 2015, 25(2):98-103.

3. Bairey Merz CN, Pepine CJ, Walsh MN, Fleg JL: Ischemia and no obstructive coronary artery disease (INOCA): developing evidence-based therapies and research agenda for the next decade. Circulation 2017, 135(11):1075-1092.

4. Sedlak TL, Lee M, Izadnegahdar M, Merz CN, Gao M, Humphries KH: Sex differences in clinical outcomes in patients with stable angina and no obstructive coronary artery disease. Am Heart $J$ 2013, 166(1):38-44.

5. Herscovici R, Sedlak T, Wei J, Pepine CJ, Handberg E, Bairey Merz CN: Ischemia and No Obstructive Coronary Artery Disease ( INOCA ): What Is the Risk? J Am Heart Assoc 2018, 7(17):e008868.

6. Camici PG, d'Amati G, Rimoldi O: Coronary microvascular dysfunction: mechanisms and functional assessment. Nat Rev Cardiol 2015, 12(1):48-62.

7. Dean J, Cruz SD, Mehta PK, Merz CN: Coronary microvascular dysfunction: sex-specific risk, diagnosis, and therapy. Nat Rev Cardiol 2015, 12(7):406-414.

8. Tsagalou EP, Anastasiou-Nana M, Agapitos E, Gika A, Drakos SG, Terrovitis JV, Ntalianis A, Nanas JN: Depressed coronary flow reserve is associated with decreased myocardial capillary density in patients with heart failure due to idiopathic dilated cardiomyopathy. J Am Coll Cardiol 2008, 52(17):1391-1398.

9. Shome JS, Perera D, Plein S, Chiribiri A: Current perspectives in coronary microvascular dysfunction. Microcirculation 2017, 24(1):1-12.

10. Chung AW, Hsiang YN, Matzke LA, McManus BM, van Breemen C, Okon EB: Reduced expression of vascular endothelial growth factor paralleled with the increased angiostatin expression resulting from the upregulated activities of matrix metalloproteinase- 2 and -9 in human type 2 diabetic arterial vasculature. Circ Res 2006, 99(2):140-148.

11. Makino A, Platoshyn O, Suarez J, Yuan JX, Dillmann WH: Downregulation of connexin40 is associated with coronary endothelial cell dysfunction in streptozotocin-induced diabetic mice. $\mathrm{Am} J$ Physiol Cell Physiol 2008, 295(1):C221-230.

12. Pan M, Han Y, Basu A, Dai A, Si R, Willson C, Balistrieri A, Scott BT, Makino A: Overexpression of hexokinase 2 reduces mitochondrial calcium overload in coronary endothelial cells of type 2 diabetic mice. Am J Physiol Cell Physiol 2018, 314(6):C732-C740.

13. Teng X, Ji C, Zhong H, Zheng D, Ni R, Hill DJ, Xiong S, Fan GC, Greer PA, Shen Z et al: Selective deletion of endothelial cell calpain in mice reduces diabetic cardiomyopathy by improving angiogenesis. Diabetologia 2019, 62(5):860-872.

14. Hinkel R, Howe A, Renner S, Ng J, Lee S, Klett K, Kaczmarek V, Moretti A, Laugwitz KL, Skroblin P et al: Diabetes Mellitus-Induced Microvascular Destabilization in the Myocardium. J Am Coll Cardiol 2017, 69(2):131-143. 
15. Nahser PJ, Jr., Brown RE, Oskarsson H, Winniford MD, Rossen JD: Maximal coronary flow reserve and metabolic coronary vasodilation in patients with diabetes mellitus. Circulation 1995, 91(3):635-640.

16. Strauer BE, Motz W, Vogt M, Schwartzkopff B: Impaired coronary flow reserve in NIDDM: a possible role for diabetic cardiopathy in humans. Diabetes 1997, 46 Suppl 2:S119-124.

17. Pitkanen OP, Nuutila P, Raitakari OT, Ronnemaa T, Koskinen PJ, lida H, Lehtimaki TJ, Laine HK, Takala T, Viikari JS et al: Coronary flow reserve is reduced in young men with IDDM. Diabetes 1998, 47(2):248-254.

18. Si R, Zhang Q, Tsuji-Hosokawa A, Watanabe M, Willson C, Lai N, Wang J, Dai A, Scott BT, Dillmann WH et al: Overexpression of p53 due to excess protein O-GlcNAcylation is associated with coronary microvascular disease in type 2 diabetes. Cardiovasc Res 2020, 116(6):1186-1198.

19. Murthy VL, Naya M, Foster CR, Gaber M, Hainer J, Klein J, Dorbala S, Blankstein R, Di Carli MF: Association between coronary vascular dysfunction and cardiac mortality in patients with and without diabetes mellitus. Circulation 2012, 126(15):1858-1868.

20. Erdogan D, Yucel H, Uysal BA, Ersoy IH, Icli A, Akcay S, Arslan A, Aksoy F, Ozaydin M, Tamer MN: Effects of prediabetes and diabetes on left ventricular and coronary microvascular functions. Metabolism 2013, 62(8):1123-1130.

21. Lopez de Silanes I, Zhan M, Lal A, Yang X, Gorospe M: Identification of a target RNA motif for RNAbinding protein HuR. Proc Natl Acad Sci U S A 2004, 101(9):2987-2992.

22. Wang J, Guo Y, Chu H, Guan Y, Bi J, Wang B: Multiple functions of the RNA-binding protein HuR in cancer progression, treatment responses and prognosis. Int J Mol Sci 2013, 14(5):10015-10041.

23. Katsanou V, Milatos S, Yiakouvaki A, Sgantzis N, Kotsoni A, Alexiou M, Harokopos V, Aidinis V, Hemberger M, Kontoyiannis DL: The RNA-binding protein Elavl1/HuR is essential for placental branching morphogenesis and embryonic development. Mol Cell Biol 2009, 29(10):2762-2776.

24. Diaz-Munoz MD, Bell SE, Fairfax K, Monzon-Casanova E, Cunningham AF, Gonzalez-Porta M, Andrews SR, Bunik VI, Zarnack K, Curk T et al: The RNA-binding protein HuR is essential for the B cell antibody response. Nat Immunol 2015, 16(4):415-425.

25. Liu L, Christodoulou-Vafeiadou E, Rao JN, Zou T, Xiao L, Chung HK, Yang H, Gorospe M, Kontoyiannis D, Wang JY: RNA-binding protein HuR promotes growth of small intestinal mucosa by activating the Wnt signaling pathway. Mol Biol Cell 2014, 25(21):3308-3318.

26. Sun K, Li X, Chen X, Bai Y, Zhou G, Kokiko-Cochran ON, Lamb B, Hamilton TA, Lin CY, Lee YS et al: Neuron-Specific HuR-Deficient Mice Spontaneously Develop Motor Neuron Disease. J Immunol 2018, 201(1):157-166.

27. Liu S, Jiang X, Lu H, Xing M, Qiao Y, Zhang C, Zhang W: HuR (Human Antigen R) Regulates the Contraction of Vascular Smooth Muscle and Maintains Blood Pressure. Arterioscler Thromb Vasc Biol 2020, 40(4):943-957.

28. Green LC, Anthony SR, Slone S, Lanzillotta L, Nieman ML, Wu X, Robbins N, Jones SM, Roy S, Owens AP, 3rd et al: Human antigen R as a therapeutic target in pathological cardiac hypertrophy. JCI Insight $2019,4(4): 1-14$. 
29. Zhou A, Xie A, Kim TY, Liu H, Shi G, Kang GJ, Jiang N, Liu M, Jeong EM, Choi BR et al: HuR-mediated SCN5A messenger RNA stability reduces arrhythmic risk in heart failure. Heart Rhythm 2018, 15(7):1072-1080.

30. Kloss S, Rodenbach D, Bordel R, Mulsch A: Human-antigen R (HuR) expression in hypertension: downregulation of the mRNA stabilizing protein HuR in genetic hypertension. Hypertension 2005, 45(6):1200-1206.

31. Abdelmohsen K, Gorospe M: Posttranscriptional regulation of cancer traits by HuR. Wiley Interdiscip Rev RNA 2010, 1(2):214-229.

32. Feigerlova E, Battaglia-Hsu SF: Role of post-transcriptional regulation of mRNA stability in renal pathophysiology: focus on chronic kidney disease. FASEB J 2017, 31(2):457-468.

33. Amadio M, Bucolo C, Leggio GM, Drago F, Govoni S, Pascale A: The PKC $\beta /$ HuR/VEGF pathway in diabetic retinopathy. Biochem Pharmacol 2010, 80(8):1230-1237.

34. Chang SH, Lu YC, Li X, Hsieh WY, Xiong Y, Ghosh M, Evans T, Elemento O, Hla T: Antagonistic function of the RNA-binding protein HuR and miR-200b in post-transcriptional regulation of vascular endothelial growth factor-A expression and angiogenesis. J Biol Chem 2013, 288(7):4908-4921.

35. Cho YE, Basu A, Dai A, Heldak M, Makino A: Coronary endothelial dysfunction and mitochondrial reactive oxygen species in type 2 diabetic mice. Am J Physiol Cell Physiol 2013, 305(10):C10331040.

36. Han Y, Cho YE, Ayon R, Guo R, Youssef KD, Pan M, Dai A, Yuan JX, Makino A: SGLT inhibitors attenuate NO-dependent vascular relaxation in the pulmonary artery but not in the coronary artery. Am J Physiol Lung Cell Mol Physiol 2015, 309(9):L1027-1036.

37. Fang JS, Angelov SN, Simon AM, Burt JM: Compromised regulation of tissue perfusion and arteriogenesis limit, in an AT1R-independent fashion, recovery of ischemic tissue in $\mathrm{Cx} 40^{-/-}$mice. $\mathrm{Am}$ J Physiol Heart Circ Physiol 2013, 304(6):H816-827.

38. Chaston DJ, Baillie BK, Grayson TH, Courjaret RJ, Heisler JM, Lau KA, Machaca K, Nicholson BJ, Ashton A, Matthaei KI et al: Polymorphism in endothelial connexin40 enhances sensitivity to intraluminal pressure and increases arterial stiffness. Arterioscler Thromb Vasc Biol 2013, 33(5):962970.

39. Wikstrom J, Gronros J, Gan LM: Adenosine induces dilation of epicardial coronary arteries in mice: relationship between coronary flow velocity reserve and coronary flow reserve in vivo using transthoracic echocardiography. Ultrasound Med Biol 2008, 34(7):1053-1062.

40. You J, Wu J, Ge J, Zou Y: Comparison between adenosine and isoflurane for assessing the coronary flow reserve in mouse models of left ventricular pressure and volume overload. Am J Physiol Heart Circ Physiol 2012, 303(10):H1199-1207.

41. Kofflard MJ, Michels M, Krams R, Kliffen M, Geleijnse ML, Ten Cate FJ, Serruys PW: Coronary flow reserve in hypertrophic cardiomyopathy: relation with microvascular dysfunction and pathophysiological characteristics. Neth Heart J 2007, 15(6):209-215. 
42. Kaul S, Jayaweera AR: Myocardial capillaries and coronary flow reserve. J Am Coll Cardiol 2008, 52(17):1399-1401.

43. Yoon YS, Uchida S, Masuo O, Cejna M, Park JS, Gwon HC, Kirchmair R, Bahlman F, Walter D, Curry C et al: Progressive attenuation of myocardial vascular endothelial growth factor expression is a seminal event in diabetic cardiomyopathy: restoration of microvascular homeostasis and recovery of cardiac function in diabetic cardiomyopathy after replenishment of local vascular endothelial growth factor. Circulation 2005, 111(16):2073-2085.

44. Lin J, Zhang L, Zhang M, Hu J, Wang T, Duan Y, Man W, Wu B, Feng J, Sun L et al: Mst1 inhibits CMECs autophagy and participates in the development of diabetic coronary microvascular dysfunction. Sci Rep 2016, 6:34199.

45. Rawal S, Munasinghe PE, Shindikar A, Paulin J, Cameron V, Manning P, Williams MJ, Jones GT, Bunton R, Galvin I et al: Down-regulation of proangiogenic microRNA-126 and microRNA-132 are early modulators of diabetic cardiac microangiopathy. Cardiovasc Res 2017, 113(1):90-101.

46. Shi Y, Lv X, Liu Y, Li B, Liu M, Yan M, Liu Y, Li Q, Zhang X, He S et al: Elevating ATP-binding cassette transporter $\mathrm{G} 1$ improves re-endothelialization function of endothelial progenitor cells via Lyn/Akt/eNOS in diabetic mice. FASEB J 2018, 32(12):6525-6536.

47. Hamed S, Brenner B, Roguin A: Nitric oxide: a key factor behind the dysfunctionality of endothelial progenitor cells in diabetes mellitus type-2. Cardiovasc Res 2011, 91(1):9-15.

48. Krishnamurthy P, Lambers E, Verma S, Thorne T, Qin G, Losordo DW, Kishore R: Myocardial knockdown of mRNA-stabilizing protein HuR attenuates post-MI inflammatory response and left ventricular dysfunction in IL-10-null mice. FASEB J 2010, 24(7):2484-2494.

49. Fu X, Zhai S, Yuan J: Endothelial HuR deletion reduces the expression of proatherogenic molecules and attenuates atherosclerosis. Int Immunopharmacol 2018, 65:248-255.

50. Ray M, Gabunia K, Vrakas CN, Herman AB, Kako F, Kelemen SE, Grisanti LA, Autieri MV: Genetic Deletion of IL-19 (Interleukin-19) Exacerbates Atherogenesis in II19-/ $\mathrm{xLdlr}^{-/-}$Double Knockout Mice by Dysregulation of mRNA Stability Protein HuR (Human Antigen R). Arterioscler Thromb Vasc Biol 2018, 38(6):1297-1308.

51. Shang J, Wan Q, Wang X, Duan Y, Wang Z, Wei X, Zhang Y, Wang H, Wang R, Yi F: Identification of NOD2 as a novel target of RNA-binding protein HuR: evidence from NADPH oxidase-mediated HuR signaling in diabetic nephropathy. Free Radic Biol Med 2015, 79:217-227.

52. Brasen JC, de Wit C, Sorensen CM: Myoendothelial coupling through $\mathrm{Cx} 40$ contributes to EDHinduced vasodilation in murine renal arteries: evidence from experiments and modelling. Acta Physiol (Oxf) 2018, 222(1):1-12.

53. Gartner C, Ziegelhoffer B, Kostelka M, Stepan H, Mohr FW, Dhein S: Knock-down of endothelial connexins impairs angiogenesis. Pharmacol Res 2012, 65(3):347-357.

54. Zheng YF, Dai DZ, Dai Y: NaHS ameliorates diabetic vascular injury by correcting depressed connexin 43 and 40 in the vasculature in streptozotocin-injected rats. J Pharm Pharmacol 2010, 62(5):615621. 
55. von Mering GO, Arant CB, Wessel TR, McGorray SP, Bairey Merz CN, Sharaf BL, Smith KM, Olson MB, Johnson BD, Sopko $\mathrm{G}$ et al: Abnormal coronary vasomotion as a prognostic indicator of cardiovascular events in women: results from the National Heart, Lung, and Blood InstituteSponsored Women's Ischemia Syndrome Evaluation (WISE). Circulation 2004, 109(6):722-725.

56. Bairey Merz CN, Handberg EM, Shufelt CL, Mehta PK, Minissian MB, Wei J, Thomson LE, Berman DS, Shaw LJ, Petersen JW et al: A randomized, placebo-controlled trial of late Na current inhibition (ranolazine) in coronary microvascular dysfunction (CMD): impact on angina and myocardial perfusion reserve. Eur Heart J 2016, 37(19):1504-1513.

57. Hill CE, Rummery N, Hickey H, Sandow SL: Heterogeneity in the distribution of vascular gap junctions and connexins: implications for function. Clin Exp Pharmacol Physiol 2002, 29(7):620-625.

58. Sandow SL, Hill CE: Incidence of myoendothelial gap junctions in the proximal and distal mesenteric arteries of the rat is suggestive of a role in endothelium-derived hyperpolarizing factor-mediated responses. Circ Res 2000, 86(3):341-346.

59. Straub AC, Zeigler AC, Isakson BE: The myoendothelial junction: connections that deliver the message. Physiology (Bethesda) 2014, 29(4):242-249.

60. Figueroa XF, Duling BR: Gap junctions in the control of vascular function. Antioxid Redox Signal 2009, 11(2):251-266.

61. Alonso F, Domingos-Pereira S, Le Gal L, Derre L, Meda P, Jichlinski P, Nardelli-Haefliger D, Haefliger JA: Targeting endothelial connexin40 inhibits tumor growth by reducing angiogenesis and improving vessel perfusion. Oncotarget 2016, 7(12):14015-14028.

62. Behrens J, Kameritsch P, Wallner S, Pohl U, Pogoda K: The carboxyl tail of Cx43 augments p38 mediated cell migration in a gap junction-independent manner. Eur J Cell Bio/ 2010, 89(11):828-838.

63. Tsang H, Leiper J, Hou Lao K, Dowsett L, Delahaye MW, Barnes G, Wharton J, Howard L, lannone L, Lang NN et al: Role of asymmetric methylarginine and connexin 43 in the regulation of pulmonary endothelial function. Pulm Circ 2013, 3(3):675-691.

64. Wang WK, Chen MC, Leong HF, Kuo YL, Kuo CY, Lee CH: Connexin 43 suppresses tumor angiogenesis by down-regulation of vascular endothelial growth factor via hypoxic-induced factor-1alpha. Int $J$ Mol Sci 2014, 16(1):439-451.

65. Chen CH, Mayo JN, Gourdie RG, Johnstone SR, Isakson BE, Bearden SE: The connexin 43/ZO-1 complex regulates cerebral endothelial F-actin architecture and migration. Am J Physiol Cell Physiol 2015, 309(9):C600-607.

66. Fang JS, Angelov SN, Simon AM, Burt JM: Cx37 deletion enhances vascular growth and facilitates ischemic limb recovery. Am J Physiol Heart Circ Physiol 2011, 301(5):H1872-1881.

67. Kotini M, Barriga EH, Leslie J, Gentzel M, Rauschenberger V, Schambony A, Mayor R: Gap junction protein Connexin-43 is a direct transcriptional regulator of $\mathrm{N}$-cadherin in vivo. Nat Commun 2018, 9(1):3846.

68. Sasaki K, Donthamsetty R, Heldak M, Cho YE, Scott BT, Makino A: VDAC: old protein with new roles in diabetes. Am J Physiol Cell Physiol 2012, 303(10):C1055-1060. 
69. Makino A, Scott BT, Dillmann WH: Mitochondrial fragmentation and superoxide anion production in coronary endothelial cells from a mouse model of type 1 diabetes. Diabetologia 2010, 53(8):17831794.

70. Pangare M, Makino A: Mitochondrial function in vascular endothelial cell in diabetes. J Smooth Muscle Res 2012, 48(1):1-26.

71. Ghosh M, Aguila HL, Michaud J, Ai Y, Wu MT, Hemmes A, Ristimaki A, Guo C, Furneaux H, Hla T: Essential role of the RNA-binding protein HuR in progenitor cell survival in mice. J Clin Invest 2009, 119(12):3530-3543.

72. Wagner C, Jobs A, Schweda F, Kurtz L, Kurt B, Lopez ML, Gomez RA, van Veen TA, de Wit C, Kurtz A: Selective deletion of Connexin 40 in renin-producing cells impairs renal baroreceptor function and is associated with arterial hypertension. Kidney Int 2010, 78(8):762-768.

73. Bosco D, Haefliger JA, Meda P: Connexins: key mediators of endocrine function. Physiol Rev 2011, 91(4):1393-1445.

\section{Tables}

Table 1. Lipid profile of control and diabetic mice.

\begin{tabular}{|lll|}
\hline & Control $(\mathrm{n}=9)$ & Diabetic $(\mathrm{n}=8)$ \\
\hline $\mathrm{TC}(\mathrm{mg} / \mathrm{dl})$ & $106.3 \pm 5.8$ & $226.2 \pm 24.2^{\star}$ \\
\hline $\mathrm{HDL}(\mathrm{mg} / \mathrm{dl})$ & $62.2 \pm 2.3$ & $100.0 \pm 2.9$ \\
\hline $\mathrm{TG}(\mathrm{mg} / \mathrm{dl})$ & $20.5 \pm 0.5$ & $25.2 \pm 0.8$ \\
\hline $\mathrm{LDL} / \mathrm{VLDL}(\mathrm{mg} / \mathrm{dl})$ & $40.0 \pm 5.2$ & $121.2 \pm 8.7^{*}$ \\
\hline
\end{tabular}

TC: plasma total cholesterol, HDL: plasma high density lipoprotein, TG: plasma triglyceride, LDL: plasma low density lipoprotein. VLDL: plasma very low-density lipoprotein. $\mathrm{N}$ shows the number of mice. Data are mean \pm SEM. ${ }^{*} P<0.05$ vs. Control.

Table 2. Body weight, plasma glucose level, and mean arterial pressure in different groups. 


\begin{tabular}{|c|c|c|c|c|}
\hline Mouse strain & $\mathbf{N}$ & BW (g) & Plasma Glucose level (mg/dl) & MAP (mmHg) \\
\hline Control & 5 & $30.0 \pm 1.0$ & $152.2 \pm 9.2$ & $107.4 \pm 2.8$ \\
\hline T2D & 5 & $49.1 \pm 2.0 *$ & $260.0 \pm 3.1^{\star}$ & $103.7 \pm 1.2$ \\
\hline Wt for Tie2-HuR ${ }^{-/-}$ & 7 & $29.8 \pm 1.3$ & $164.6 \pm 7.4$ & $92.8 \pm 2.4$ \\
\hline Tie2-HuR ${ }^{-/-}$ & 6 & $28.1 \pm 1.4$ & $166.2 \pm 14.8$ & $95.3 \pm 2.7$ \\
\hline Wt for $\mathrm{C} \times 40^{-/-}$ & 5 & $24.0 \pm 0.6$ & $106.6 \pm 2.8$ & $99.0 \pm 2.2$ \\
\hline $\mathrm{C} \times 40^{-/-}$ & 5 & $23.0 \pm 0.4$ & $122.8 \pm 4.8^{\star}$ & $116.6 \pm 4.1^{*}$ \\
\hline Dia-Wt & 8 & $47.0 \pm 1.6$ & $265.4 \pm 17.8$ & $88.2 \pm 3.6$ \\
\hline Dia-TG & 6 & $43.6 \pm 2.3$ & $210.3 \pm 14.1^{\star}$ & $89.7 \pm 2.2$ \\
\hline
\end{tabular}

BW: body weight, MAP: mean arterial pressure. Plasma glucose level was measured in mice without fasting. Data are presented as mean $\pm S$.E. Student's $t$-test was carried out to determine the significance between groups.

\section{Figures}



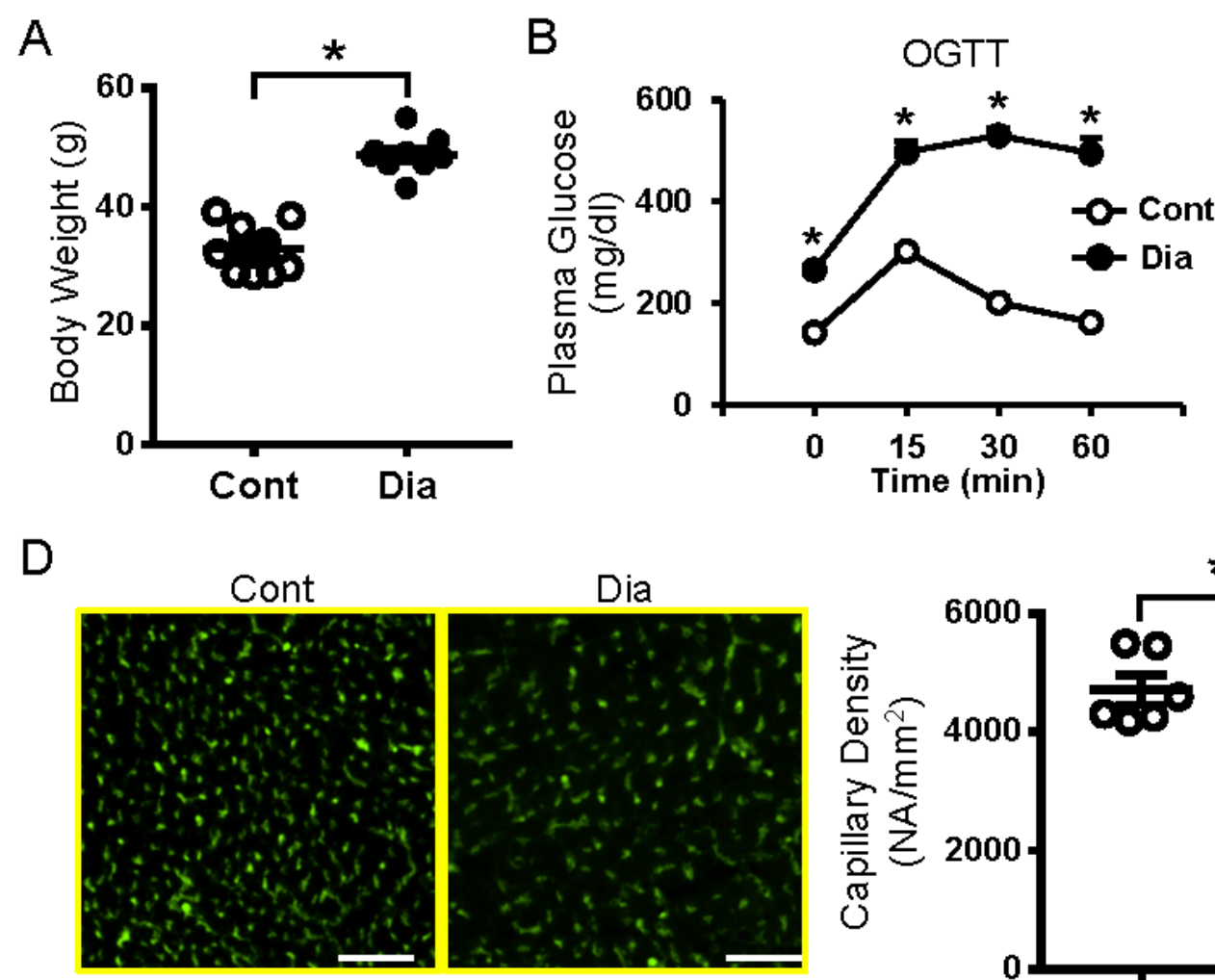
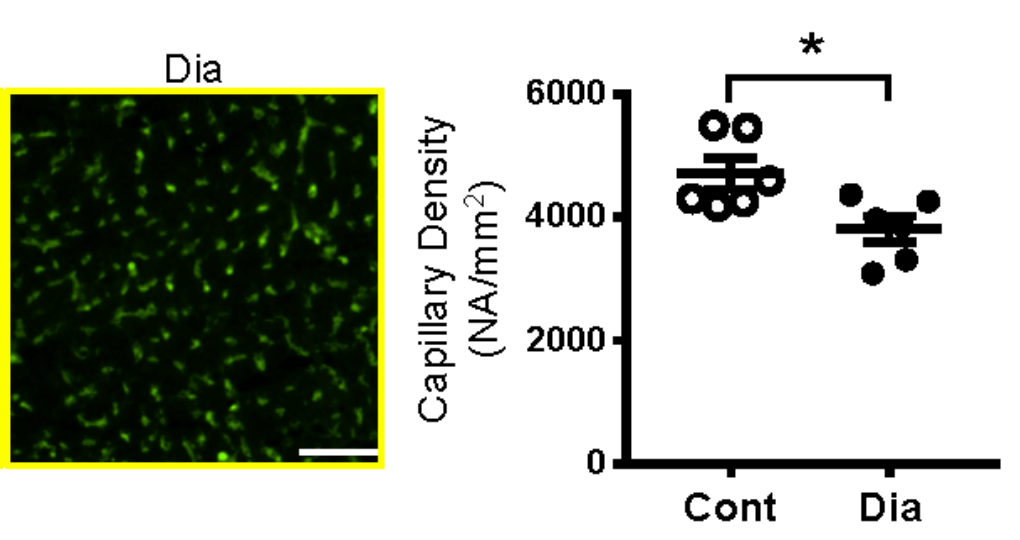

\section{Figure 1}

Phenotype of inducible Type 2 diabetic mice. A: Body weight with fasting. Control mice (Cont, nmice=9); diabetic mice (Dia, nmice=9). B: Oral glucose tolerance test (OGTT). Nmice=9 per group. C: Coronary flow velocity reserve (CFVR). Cont, nmice=8; Dia, nmice=7. D: Representative photomicrographs (left) showing capillary density. ECs were stained by BS-lectin-FITC (green, a marker of ECs). Bar=50 $\mu \mathrm{m}$. Averaged data (right) showing capillary density in control $(n m i c e=6)$ and diabetic $(n m i c e=6)$ mice. Data are mean \pm SEM. ${ }^{*}<0.05$ vs. Cont. Statistical comparison between time-dependent curves was made by two-way ANOVA with Bonferroni post hoc test. Unpaired Student's t-test (2-tailed) was used for comparisons of two experimental groups. 

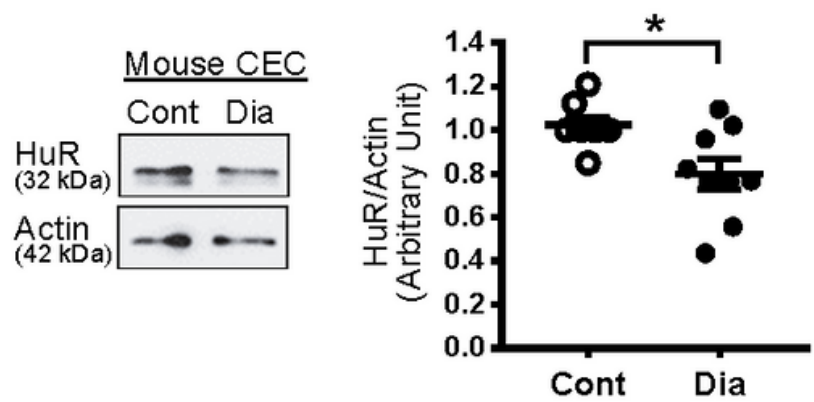

B
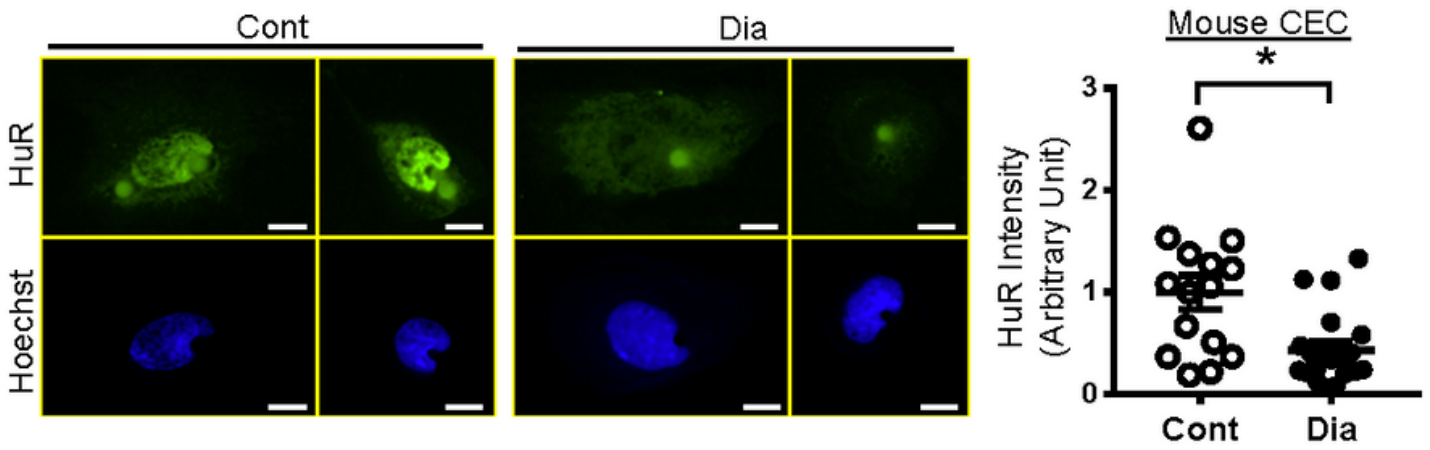

C

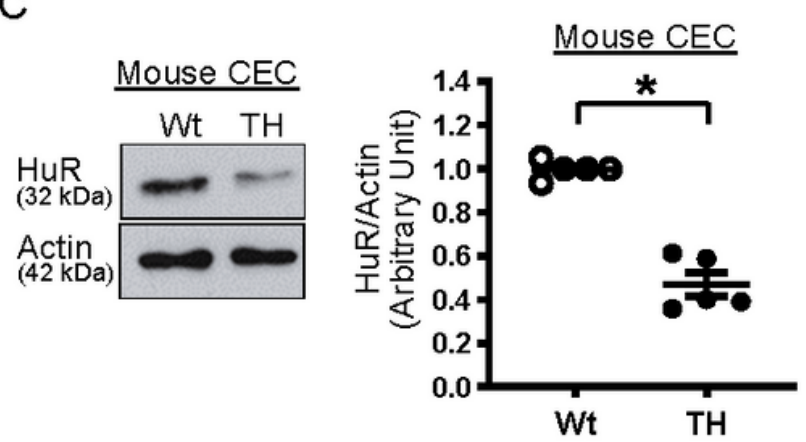

D

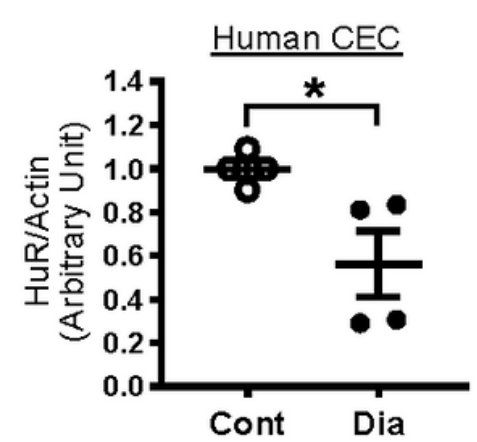

Figure 2

HuR protein levels in cardiac endothelial cells from control and diabetic mice and patients. A: Western blots showing HuR and Actin protein levels in mouse cardiac endothelial cells (CECs) (left panel). The right dot plot shows HuR protein level normalized to Actin. Cont, nmice $=8$; Dia, nmice $=9$. ${ }^{\star} \mathrm{P}<0.05$ vs. Cont. B: Photomicrographs show typical images of HuR expression in CECs. CECs were stained with HuR (green) and Hoechst (nuclear staining, blue). The right dot plot shows averaged data of HuR intensity. Bar $=10 \mu \mathrm{m}$. Cont, ncells $=15$; Dia, ncells $=21$. Three mice were used per group. ${ }^{*} \mathrm{P}<0.05$ vs. Cont. $C$. Representative image of Western blots showing HuR and Actin protein levels in CECs from Tallyho mice ( $\mathrm{TH}$, spontaneous T2D mice, nmice $=5)$ and wild-type mice $(\mathrm{Wt}$, nmice $=5)$ (left panel). Dots plot shows summarized data (right panel). ${ }^{*} \mathrm{P}<0.05 \mathrm{vs}$. Wt. D. HuR protein level in human CECs from control patients (Cont, npatients $=4$ ) and diabetic patients (Dia, npatients $=4)$. ${ }^{*} P<0.05$ vs. Cont. Data are mean \pm SEM. Unpaired Student's t-test (2-tailed) was used for comparisons of two experimental groups. 
A

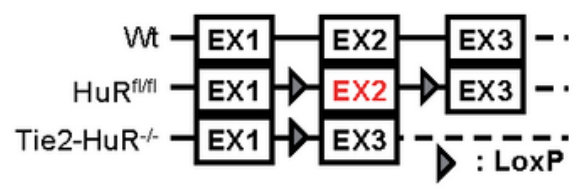

D
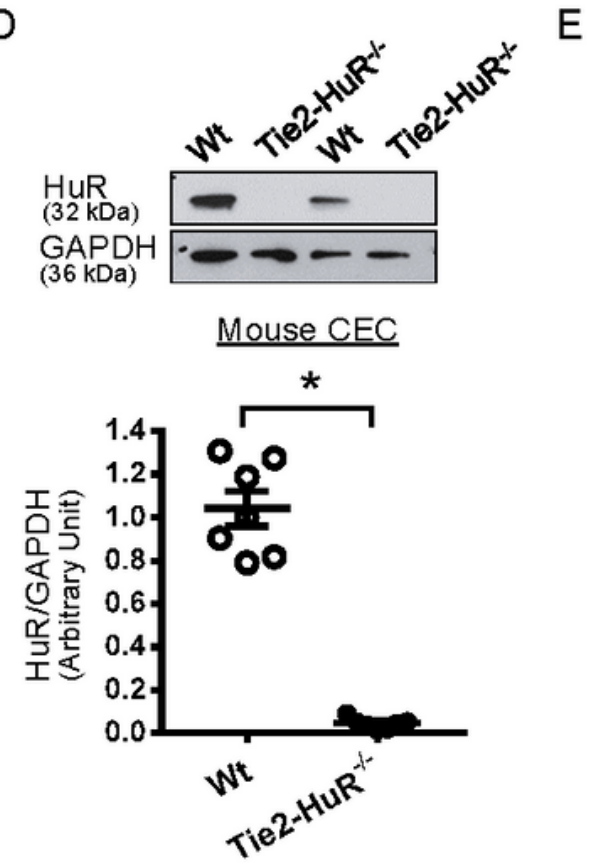

$\mathrm{F}$

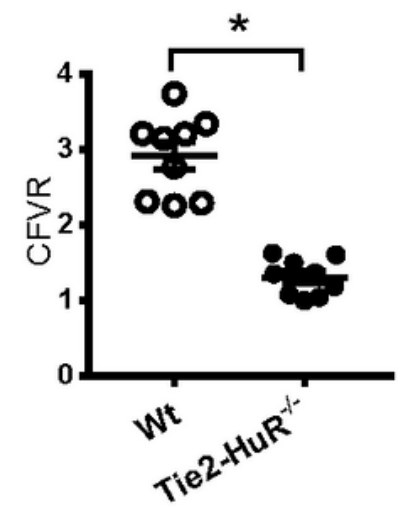

$E$

G
B
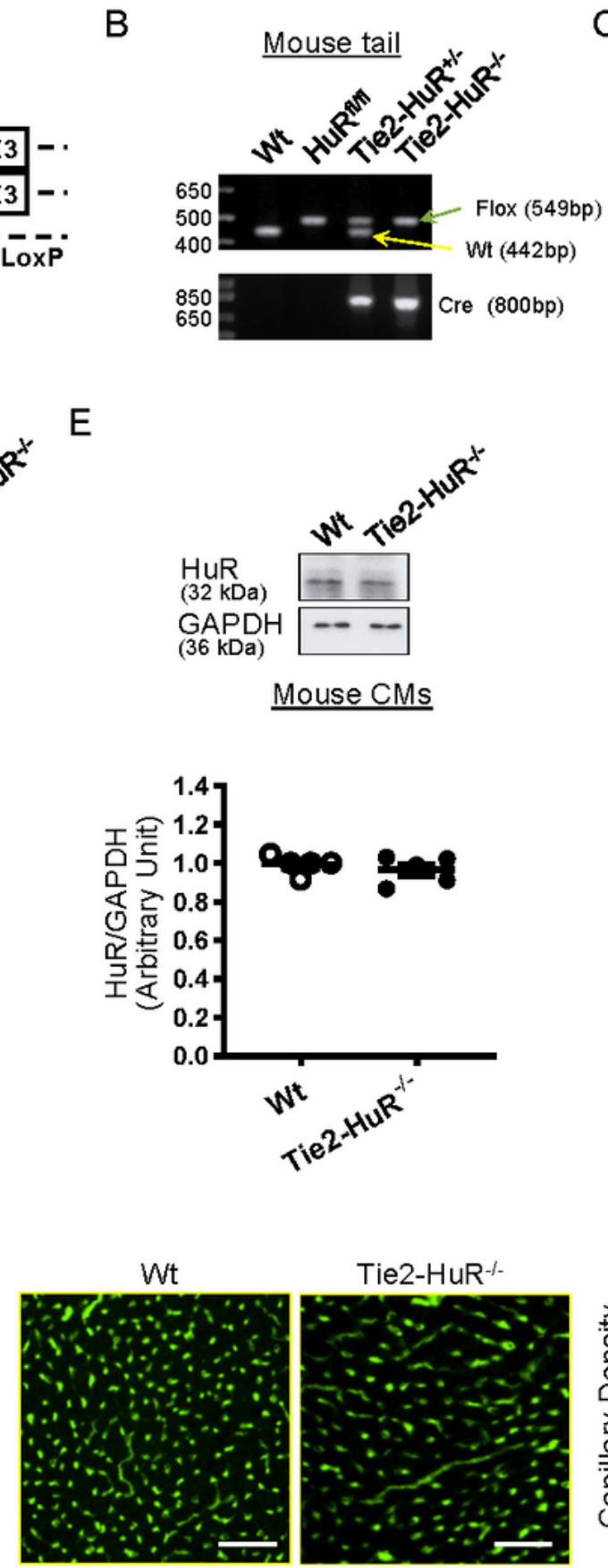

Tie2-HuR ${ }^{-/-}$
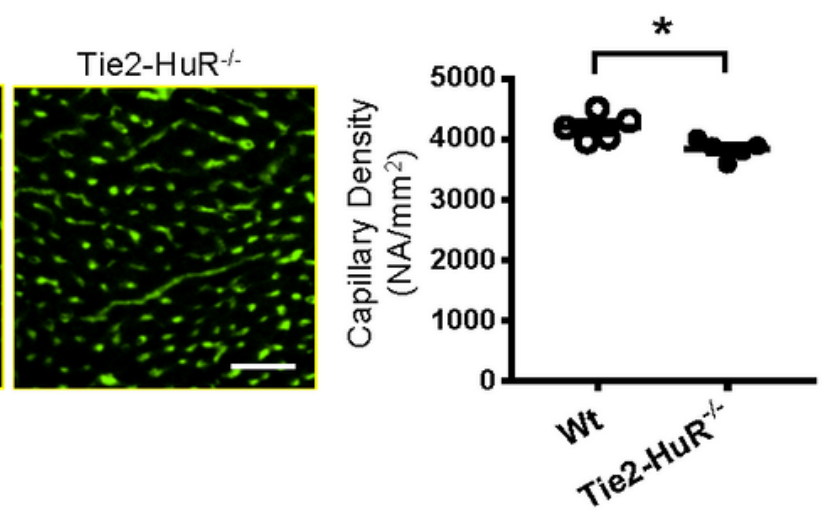

\section{Figure 3}

Generation and phenotyping of endothelium-specific HuR knockout mice. A: Diagrams depict the genomic region surrounding exon 2 (EX2) of the wild-type (Wt) HuR allele, the HuR-loxP (HuRfl/fl) allele with two loxP sites (arrowheads) flanking exon 2, and the deleted (Tie2-HuR-/-) allele that was produced by crossing HuRfl/fl mice with Tie2-Cre (Tie2-driven Cre-recombinase overexpressing) mice. B: PCR analysis of genomic DNA from tail samples indicates floxed, HuR deletion, and Cre bands in HuRfl/fl, 
Tie2-HuR+/-, and Tie2-HuR-/- mice. C: HuR mRNA levels in CECs determined by real-time PCR. Nmice=8 per group. D: HuR protein levels in CECs determined by Western blot. The bottom dot plot shows HuR protein level normalized to GAPDH. Nmice=7 per group. E: HuR protein levels in mouse cardiac myocytes (CMs). Nmice=5 per group. F: CFVR. Nmice=9 per group. G: Representative photomicrographs (left) and summarized data (right) of capillary density. Bar $=50 \mu \mathrm{m}$. Nmice $=5$ per group. Data are mean \pm SEM. ${ }^{*} \mathrm{P}<0.05$ vs. Wt. Unpaired Student's t-test (2-tailed) was used for comparisons of two experimental groups.

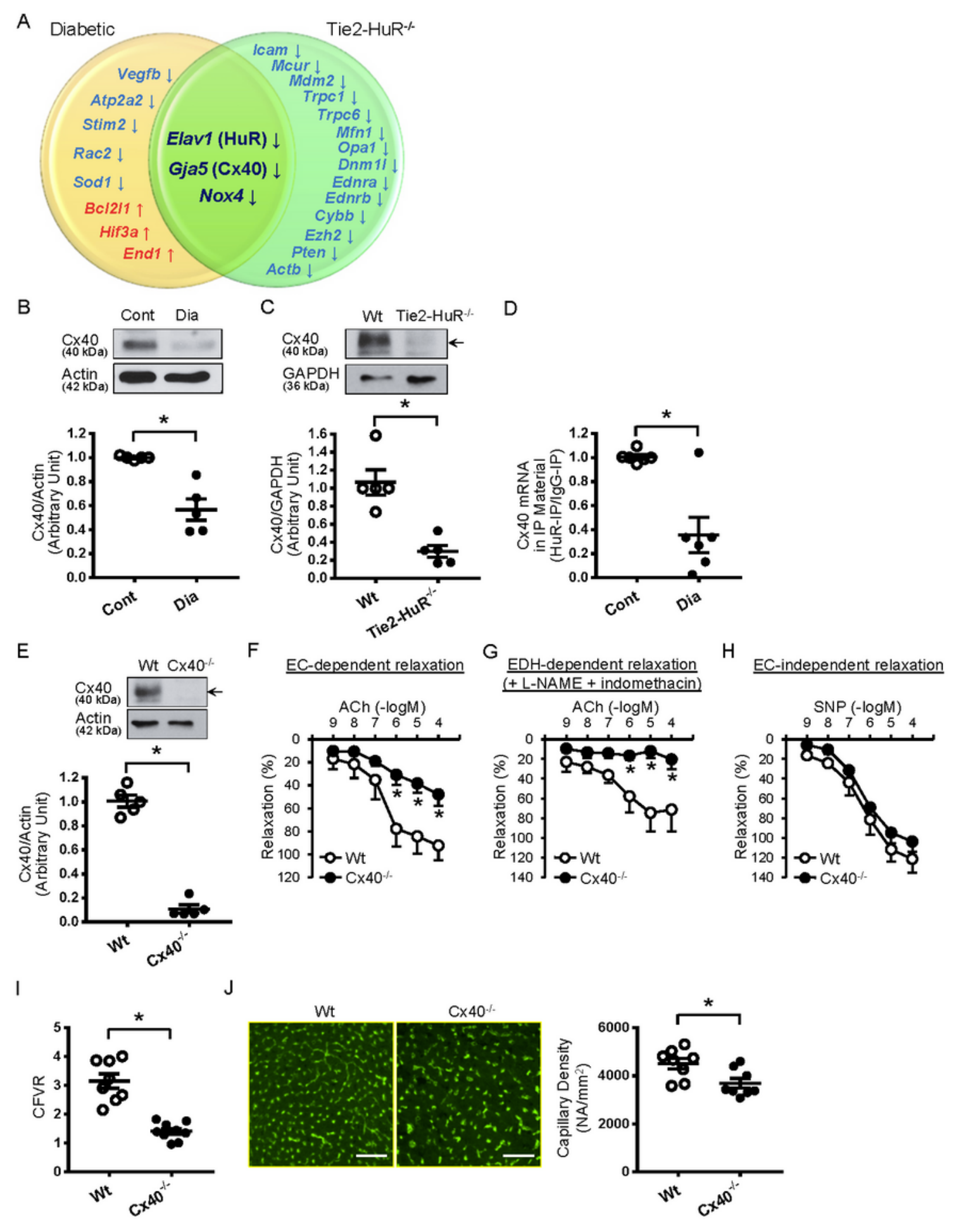

Figure 4 
Identification of HuR-regulated genes and the effect of $\mathrm{Cx} 40$ deletion on coronary microvascular function. A: mRNA levels were compared between control and diabetic mice (nexperiment $=6$ [12 mice per group]) and between Wt and Tie2-HuR-/- mice (nexperiment=6 [12 mice per group]) (Additional File 2: Fig. S4 and S5). Blue text indicates downregulated genes, and red text indicates upregulated genes. B: Western blots showing $\mathrm{Cx} 40$ and Actin protein levels in CECs from control and diabetic mice (top panel). The bottom dot plot shows $\mathrm{C} \times 40$ protein level normalized to Actin. Nmice $=5$ per group. $\mathrm{C}$ : Western blots showing $\mathrm{Cx} 40$ and GAPDH protein levels in CECs from Wt mice and Tie2-HuR-/- mice (top panel). The bottom dot plot shows $\mathrm{Cx} 40$ protein level normalized to GAPDH. Nmice $=5$ per group. D: Binding of $\mathrm{C} \times 40 \mathrm{mRNA}$ to HuR protein determined by ribonucleoprotein immunoprecipitation. mRNA levels were determined by real-time PCR. Nmice 6 per group. E: Western blots showing Cx40 and Actin protein level in CECs (top panel). The bottom dot plot shows $\mathrm{Cx} 40$ protein level normalized to Actin. Nmice=5 per group. F: Endotheliumdependent relaxation evaluated by acetylcholine (ACh)-induced relaxation in coronary arteries (CAs). Nmice=7 per group. G: Endothelium-derived hyperpolarization (EDH)-dependent relaxation in CAs determined by ACh administration in the presence of L-NAME (an endothelial NO synthase inhibitor, 10$4 \mathrm{M}$ ) and indomethacin (a cyclooxygenase inhibitor, 10-5M). Nmice=7 per group. H: Endotheliumindependent relaxation evaluated by sodium nitroprusside (SNP)-induced relaxation in CAs. Nmice=7 per group. I: CFVR. Wt, nmice=8; Cx40-/-, nmice=9. J: Representative photomicrographs (left) and summarized data (right) of capillary density. Bar $=50 \mu \mathrm{m}$. Nmice $=8$ per group. Data are mean \pm SEM. ${ }^{*} \mathrm{P}<0.05$ vs. Cont or Wt. Statistical comparison between dose-response curves was made by two-way ANOVA with Bonferroni post hoc test. Unpaired Student's t-test (2-tailed) was used for comparisons of two experimental groups. 
A

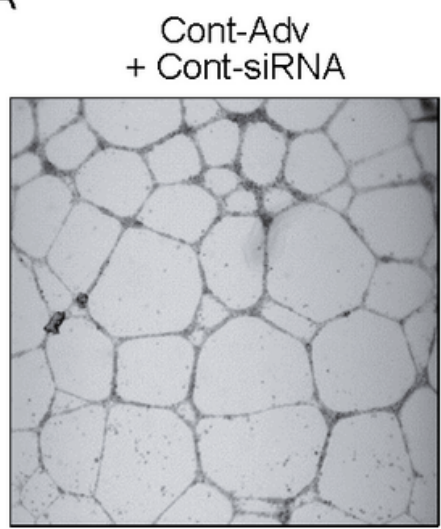

B

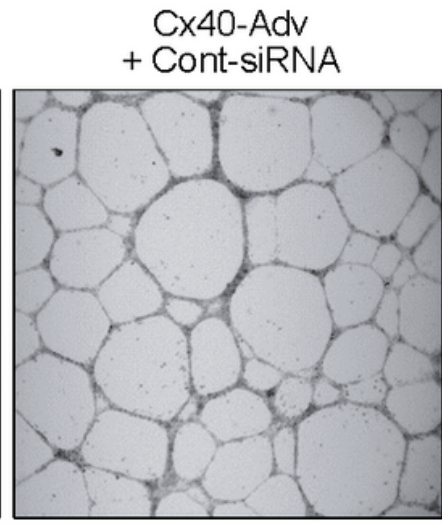

C
Cont-Adv + HuR-siRNA

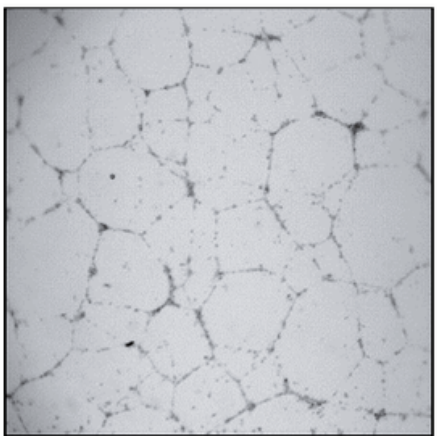

D
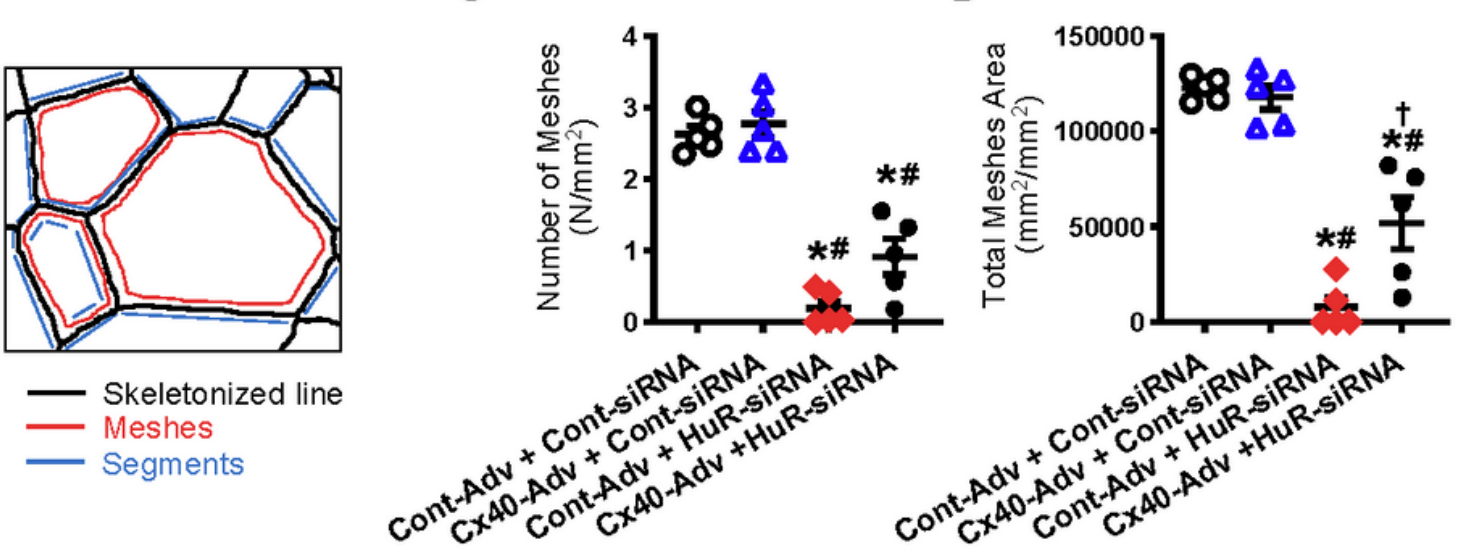

- Skeletonized line

- Meshes

— Segments

E

$F$

G
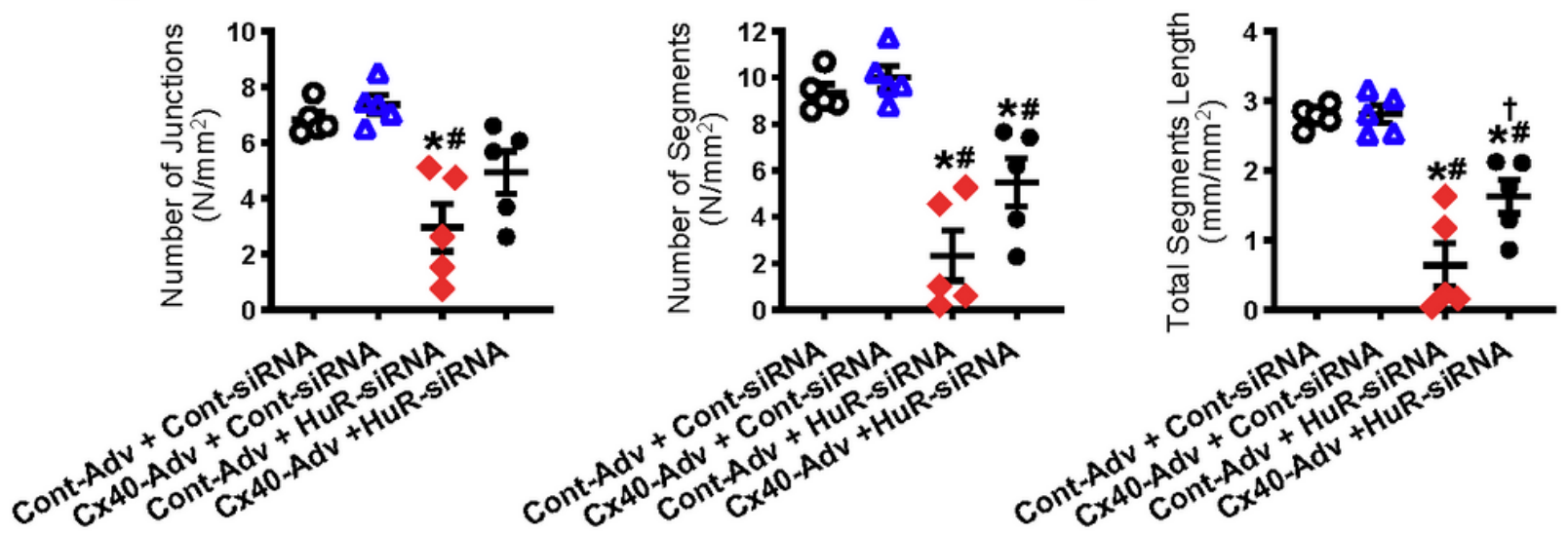

Figure 5

Effect of $\mathrm{Cx} 40$ overexpression and HuR inhibition on tube formation in human CECs. A: Representative photograph image of tube formation. B: Schematic diagram of tube formation parameters. C-G.

Summarized data of the number of meshes (C), total meshes area (D), junction numbers (E), number of segments $(F)$, and total segments length $(G)$ in human CECs with or without $C x 40$ overexpression (Contadenovirus [Adv] or Cx40-Adv, 100 pfu/cell, 96 hours) in the absence or presence of HuR inhibition (ContsiRNA or HuR-siRNA, 100 nM, 72 hours). Nexperiments $=5$ per group. ${ }^{*} \mathrm{P}<0.05$ vs. Cont-Adv + Cont-siRNA, 
$\# \mathrm{P}<0.05$ vs. Cx40-Adv + Cont-siRNA, $+\mathrm{P}<0.05$ vs. Cont-Adv + HuR-siRNA. Data are mean \pm SEM.

Statistical comparison between four groups was made by one-way ANOVA with Bonferroni post hoc test.

A
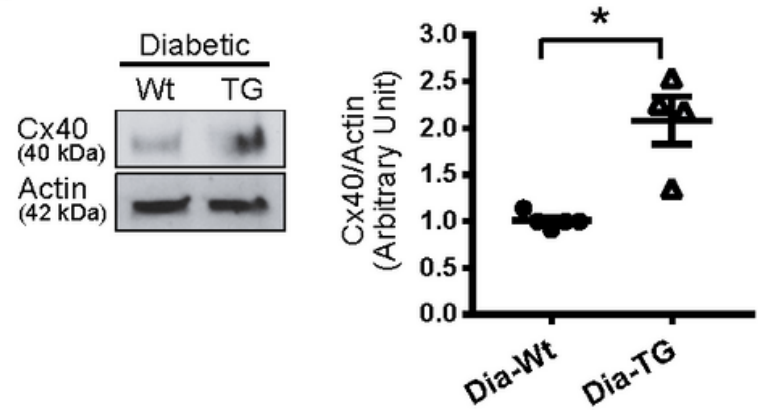

B

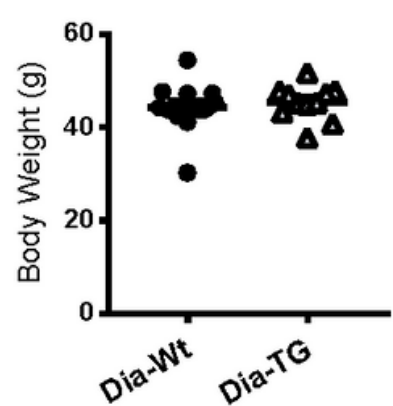

C

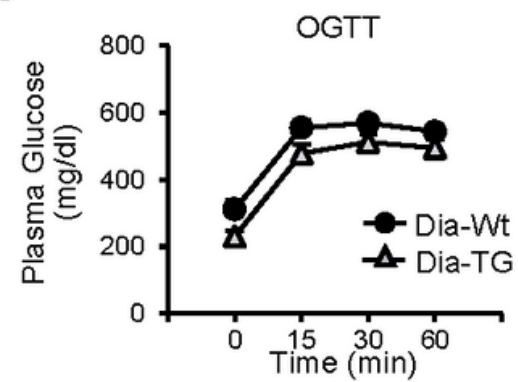

D $\mathrm{E}$

EC-dependent relaxation $\mathrm{ACh}(-\log \mathrm{M})$

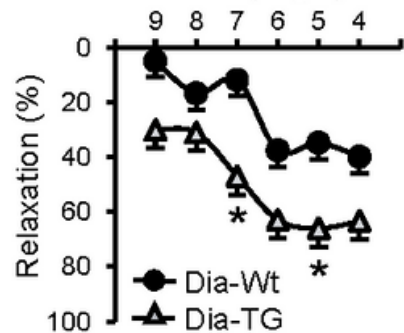

EC-independent relaxation SNP $(-\log M)$

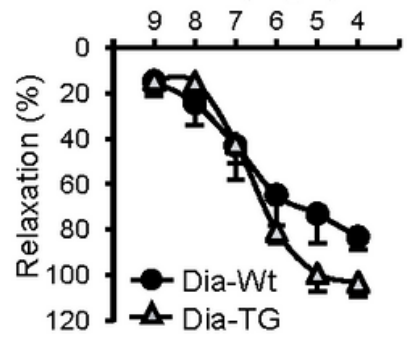

F

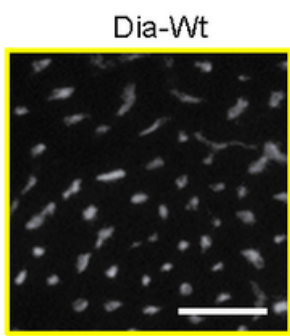

Dia-TG

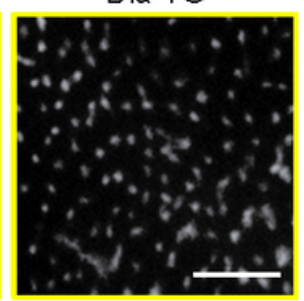

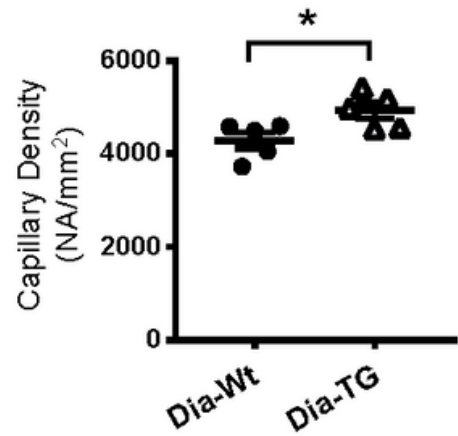

G

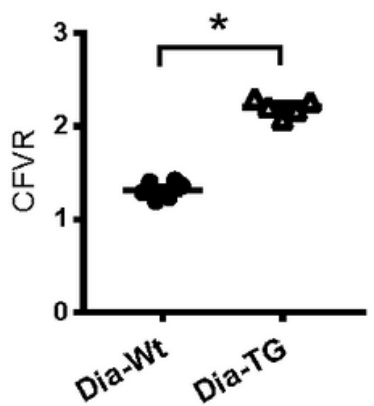

Figure 6

Cx40 overexpression in ECs increased CFVR and capillary density. A: Western blots showing Cx40 and Actin protein levels in CECs (left panel). The right dot plot shows Cx40 protein level normalized to Actin. Diabetic Wt (Dia-Wt), nmice=5; Cx40-overexpressing diabetic mice (Dia-TG), nmice=4. B: Body weight. Dia-Wt, nmice=12; Dia-TG, nmice=11. C: OGTT. Dia-Wt, nmice=12; Dia-TG, nmice=11. D: Endotheliumdependent relaxation evaluated by ACh administration in CAs. Dia-Wt, nmice=5; Dia-TG, nmice=7. E: Endothelium-independent relaxation evaluated by SNP administration in CAs. Dia-Wt, nmice=5; Dia-TG, nmice $=7$. F: Representative photomicrographs (left) showing capillary density. ECs were stained by BSlectin-TRITC since this strain also expresses EGFP. Bar=50 $\mu \mathrm{m}$. Averaged data (right) showing capillary density in Dia-Wt (nmice=5) and Dia-TG (nmice=5) mice. G: CFVR. Dia-Wt, nmice=6; Dia-TG, nmice=5. Data are mean \pm SEM. ${ }^{*} \mathrm{P}<0.05$ vs. Dia-Wt. Statistical comparison between time-dependent curves was 
made by two-way ANOVA with Bonferroni post hoc test. Unpaired Student's t-test (2-tailed) was used for comparisons of two experimental groups.

\section{Supplementary Files}

This is a list of supplementary files associated with this preprint. Click to download.

- AdditionalFile1.pdf

- AdditionalFile2.pdf

- AdditionalFile3.pdf 